\title{
ARQUEOLOGÍA DE JAUJA, PERÚ: DEL INTERMEDIO TEMPRANO AL INTERMEDIO TARDÍO (Resultados de la temporada de campo 1986)
}

\author{
CHRISTINE A. HASTORF \\ Universidad de Minnesota, Minneapolis \\ TIMOTHY K. EARLE \\ Universidad de California, Los Angeles \\ HERBERT E, WRIGHT JR. \\ Universidad de Minnesota, Minneapolis \\ LISA LE COUNT \\ Universidad de California, Los Angeles \\ BLENN RUSSELL \\ Universidad de California, Los Angeles \\ ELSIE SANDEFUR \\ Universidad de California, Los Angeles
}





\section{I. - INTRODUCCIÓN}

Las investigaciones arqueológicas llevadas a cabo en 1988 fueron diseñadas para examinar a los Sausa, un grupo cultural pre inka, conocido con el nombre de Wanka, asentado en las serranías de los Andes Centrales del Perú. La información recuperada incluye fundamentalmente datos económicos, geológicos y sociales, correspondientes principalmente al registro arqueológico ubicada entre el Intermedio Temprano (200 AC - 700 AD) y al Intermedio Tardío (1000 - 1480 AD). A pesar que los resultados son preliminares, este trabajo contiene datos nuevos sobre el desenvolvimiento socioeconómico de los Sausa, y es parte de un estudio a largo plazo iniciado en 1977 por el Proyecto de Investigaciones Arqueológicas en el Alto Mantaro (PIAAM) (Earle, D'Altroy, Le Blanc, Hastorf y La Vine 1980, D’Altroy 1981; Le Blanc 1980; Hastorf y Hastorf 1983). Como se comprobará en las páginas que siguen, en esta ocasión presentaremos algunas de las nuevas evidencias recuperadas en 1986 así como los análisis logrados hasta la fecha. Aún cuando estos estudios se vinculen al esquema cultural de los Andes en su conjunto, esta monografía no se ocupa de este aspecto, concentrándose únicamente en los últimos descubrimientos.

La meta propuesta en la temporada de trabajos realizados en 1988 consistió en estudiar las actividades de la unidad doméstica en función de la intensificación económica y los cambios en la estructura sociopolítica desde el nivel aldeano, hasta la organización de los asentamientos más allá de ese nivel. En base a esta perspectiva intentamos entender cómo y por qué aumenta la desigualdad a medida que se desarrolla el liderazgo político. También averiguamos cómo se ubican los Sausa en el patrón general andino y en los principales cambios sociales a través del tiempo. Finalmente, como parte de la situación andina, nos interesa conocer los cambios climáticos y ambientales que pudieron afectar a la población.

Nuestro proyecto ha centrado sus esfuerzos en la sección norte de los Wanka, conocida localmente con el nombre de Sausa o Xauxa, para examinar dos problemas fundamentales. Primero, averiguar el surgimiento de la estratificación social y económica de una sociedad en particular. Segundo, estudiar los efectos económicos y políticos de la incorporación de la sociedad Wanka al imperio Inka. El proyecto, por otro lado, se base directamente en los estudios pioneros de Ramiro Matos Mendieta y Jeffrey M. Parsons realizados en 1978 - 1988 (Matos 1959, 1963, 1972, 1975; Matos y Parsons 1979; Parsons 1976; Parsons y Matos 1978; Parsons y Hastings 1988), aunque también existen contribuciones de otros investigaciones (Lumbreras 1957, 1959; Flores 1959; Browman 1970; Fung 1959; etc.). En 1988 estudiamos el primer problema: cambio y continuidad a través del tiempo.

Según los datos recuperados antes de nuestros estudios en la región, se percibían interesantes y sugestivas tendencias de cambio en el desarrollo agrícola y en los patrones de asentamiento. Sin embargo, la evidencia era insuficiente como para interpretar dichos cambios (Browman 1970; Parsons 1978; Parsons y Hasting 1980). En consecuencia, para estudiar la evolución social y entender el desarrollo local de Sausa, debimos refinar y caracterizar la secuencia alfarera y los patrones de asentamiento.

Puesto que tenemos interés en producción, consumo o intercambio doméstico en detalle, consideraremos que es más afectivo concentrarse en la unidad productiva. Por consiguiente, nos propusimos examinar al complejo residencial o doméstico, el cual definimos como un lugar o espacio donde se reúnen pequeños grupos de personas para vivir y extraer recursos para la producción y el consumo (Hayden y Cannon 1982). Previamente a 1988 excavamos complejos domésticos en sitios del Intermedio Tardío y el Horizonte Tardío (Earle at al. 1987), en base a los cuales hemos definido la unidad doméstica como un complejo cercado con una o más estructuras. Las excavaciones hechas en 1985 en el asentamiento de Pancán pusieron al descubierto varios de estos complejos, indicando que el concentrarnos en los complejos domésticos significa recuperar datos concretos sobre actividades productivas así como la organización supradoméstica y vecinal entre los asentamientos.

Como se constatará más adelante, una parte esencial de nuestro proyecto incluye 
también la reconstrucción de las condiciones climáticas y la flora a través del tiempo. Esta tarea es crucial para conocer el impacto de la sociedad sobre el ambiente, el cual difiere de los cambios climáticos. Adicionalmente intentamos describir la influencia de la sociedad sobre el ambiente así como las perturbaciones climáticas que afectaron a la población Sausa desde el período Formativo. Advertimos al respecto que nuestro interés por datos ambientales a través de la secuencia no supone considerar al ambiente como la causa del desarrollo cultural. Más bien, puesto que los Andes poseen una compleja configuración ambienta, queremos entender su impacto incluyendo los aspectos apropiados en nuestra discusión sobre el desarrollo y el cambio cultural.

El reconocimiento arqueológico abarcó toda la región a excepción de las zonas montañosas del este, aledañas a Quero (Fig. 1). Las excavaciones de Pancán se ubican a $4 \mathrm{~km}$ al norte de Jauja, orilla sur este de la laguna de Paca. Los propietarios del lugar nos informaron que este lugar recibe el nombre de Ninancaya "lugar para quemar", en idioma Quechua. El sitio está deshabitado desde la época Inka y hoy es utilizado para la agricultura. El estudio geológico incluye a su vez la laguna Paca (considerando el ambiente local del sitio) y los glaciales de la cordillera oriental y occidental.

\section{LA REGIÓN DE ESTUDIO}

Se ubica en la provincia de Junín, distrito de Jauja al este e Lima y a $250 \mathrm{~km}$ de la Costa. Se compone de pequeños valles con colinas rocosas y de pendiente pronunciada, que ascienden a los escarpados picos nevados, los cuales se hallan cortados naturalmente por pequeños tributarios. Esta zona se encuentra en el lado Norte del valle del Mantaro (Suanca Huamaní), entre la puna de Huricolca al Norte y al límite Sur del grupo étnico Sausa, en las inmediaciones del pueblo moderno de Sincos, parte central del Mantaro. Los límites orientales y occidentales están representados por tierras cultivables conforme ascienden a la cordillera a ambos lados del valle. Estas se extienden en el Oeste sobre la localidad de Tajana, y en el Este hasta las cercanías de Quero (fig. 1). La zona tiene 80 por $1 \mathrm{~km}$ y se ubica entre 3300 y 4200 m.s.n.m.

Existen cinco zonas ecológicas que actualmente se utilizan diferencialmente; ellas son: las tierras del propio valle; valles tributarios, pequeños, ligeramente elevados situados en el Norte y en el Este; las laderas de los cerros; las altiplanicies accidentadas; laderas de la puna baja. Cada una de estas divisiones ambientales contiene micro zonas, aunque en general se correlacionan al uso que reciben hoy en día (Pulgar Vidal 1987; Mayer 1978; Hastorf 1988). La agricultura de secano predomina en todas las zonas, practicándose agricultura con regadío en los valles y en las laderas aledañas a manantiales. En esta región el maíz se produce hasta alturas de 3300 y los tubérculos hasta los 4000 m.s.n.m., todavía se producen todos los cultivos andinos, agregándose a éstos el trigo y la cebada conforme a una secuencia de cultivo rotativo.

Actualmente la región está cubierta por vegetación herbácea y pastos, con árboles y arbustos en los linderos de los campos de cultivo, cerca de los manantiales y en los valles abrigados. La mayoría de árboles que hoy se van fueron introducidos en tiempos modernos, por lo cual es fácil imaginar una distribución muy diferente de los árboles en el pasado. Existe marcada evidencia de una sustancial erosión de los suelos de esta región, proceso que pudo ocurrir especialmente en los últimos dos mil años, pues los lagos locales tienen solo 2500 años de antigüedad (Comunicación personal de Wright en 1987). Los arbustos pequeños y foros son de origen local y corresponden predominantemente a tipos que sobreviven en ambientes disturbados. Un conjunto diferente de plantas crece en las márgenes de los manantiales, canales y lagos, pero nunca alejados de un asentamiento. Esta situación sugiere una larga manipulación del ambiente por parte de los pobladores.

El suelo de esta región es aluvial producto de una serie de derretimientos glaciales, y también depósitos no consolidados creados en las pronunciadas pendientes de las montañas circundantes. Algunas secciones de las partes altas presentan evidencia de intemperismo in situ a través del tiempo; en cambio, otras áreas, 
especialmente de los valles, sugieren que han recibido sedimentación recientemente (en los últimos 2000 años). La cordillera oriental está compuesta de varios tipos de rocas sedimentarias e ígneas; la cordillera occidental exhibe caliza del cretáceo. Por consiguiente, ambos lados de la región intermontana son totalmente distintos en lo que a suelos se refiere. También existen evidencias de una serie de fallas pequeñas así como numerosos manantiales en la base de los cerros que circundan los valles.

\section{EsTUDIOS EFECTUADOS EN 1986}

A continuación damos a conocer los resultados logrados por los distintos especialistas.

\section{III.a. Geología de la Región (H. .E.Wright Jr.)}

Los cambios climáticos recientes de los Andes peruanos se reflejan en los avances y retrocesos de los pequeños glaciales de las cadenas montañosas situadas a elevaciones mayores de 4800 m. Una fluctuación glacial significativa se manifiesta por la presencia de formaciones geológicas exentas de flora. Estas características pueden compararse con las viejas y estables formaciones resultantes de la última glaciación sucedida hace más de 1000 años. Uno de los principales objetivos de la temporada de 1986 consistió en recuperar material para fechar por radio carbono los últimos eventos glaciales. Según estudios previos efectuados en las montañas situadas al Oeste de Junín, estas fluctuaciones climáticas se produjeron antes del año 830 AD (Bright 1980; 1984).

La zona seleccionada para el análisis fue el nevado de Huaytapallana, al este de Jauja. Los rasgos glaciales más recientes de este nevado fueron graficados en un mapa con apoyo de fotografías aéreas tomadas en 1981 por el Servicio Aerofotográfico Nacional del Perú, Base FAP Las Palmas, Barranco. Cuando la nieve estuvo en su máximo depositó una morrena terminal y sedimentos por efectos del derretimiento situado más allá de la morrena. $\mathrm{Al}$ retroceder la capa de nieve desde su mo- rrena terminal, el área frontal quedó libre de deshielos dando lugar al desarrollo de musgos en dicha sección. Los fechados radiocarbónicos de la base de esta vegetación indican que los glaciales retrocedieron en cinco localidades diferentes entre los años 600-1700 AD. También se estudió una sección de la parte oeste del Nevado Panchacoto, al Sur de La Oroya. Las fechas radiocarbónicas provenientes de la parte inferior de la zona de vegetación se ubican entre 1300-1600 AD.

Además de estudiar los nevados recogimos muestras de sedimentos lacustres y turbera pantanosa de la laguna Paca y la orilla pantanosa. Esta laguna se halla junto a Pancán, cerca de Jauja y su lecho se formó, al parecer en la parte aluvial del río Mantaro, cuando las gravas glaciales, procedentes de la Cordillera occidental depositaron materiales en la cabecera de la garganta del río Mantaro. Sin embargo, las fechas radiocarbónicas para dos secciones de la parte inferior del sedimento lacustre tienen solo 2550 y 5300 años A. P. de manera que el lago puede tener otro origen, tal vez por una contracción o depresión de la roca madre tipo caliza. La sección superficial sur del lago es pantanosa tiene vegetación pero en la parte propiamente central alcanza alrededor de 14 $\mathrm{m}$ de profundidad. Su margen sureste está pegada al pequeño abanico fluvial sobre el cual se ubica Pancán.

Cuando excavamos en 1988 constatamos que dos metros de la sección profunda del depósito cultural de Pancán se ubican debajo el nivel actual del lago. Aparentemente el nivel natural del lago estaba un metro más alto hasta que se construyó un canal hace varias décadas, en su esquina sureste. Sin embargo, no existen evidencias indicando que el lago cubrió alguna vez al asentamiento de Pancán. El aumento de nivel del lago puede deberse a nuevas disposiciones de abanicos de sedimento aluvial originados en la llanura intensamente cultivada de Jauja y los cerros adyacentes del Oeste. Posiblemente este aumento se produjo en décadas pasadas o quizá algunas centurias, más no en la época que Pancán estuvo habitado.

Por otro lado, los niveles inferiores de Pancán se componen de sedimento aluvial proveniente del abanico que se extiende desde los 
cerros hacia el oriente. Se encontraron artefactos en el sedimento, lo que indicaría que en las fases tempranas de ocupación este lugar estuvo sujeto a inundaciones procedentes del este.

\section{III.b. Reconocimiento y Recolección de Superficie (Timothy K. Earle)}

La recolección de superficie tuvo como objetivo refinar cambios en los patrones de asentamiento de la región Sausa, Alto Mantaro. El trabajo consistió en revisitar los sitios identificados por J. Parsons en 1975 y 1976 (Parsons 1976; Parsons y Hastings 1988). Se procuró definir el área habitacional en cada asentamiento, calcular la población y recuperar suficiente alfarería para precisar la edad de cada asentamiento y construir una historia más precisa del patrón de asentamiento. El objetivo final es describir el crecimiento de la población, su distribución con respecto a los recursos para la subsistencia, la organización regional de los Sausa y la articulación de esta sociedad con otros grupos, sobre todo con Pachacamac, Wari o Inka.

Anteriormente, Catherine Scott (1981) hizo una recolección en sitios correspondientes a fines del Intermedio Tardío (Wanka II) y del Horizonte Tardío (Wanka III) de la cuenca de Yanamarca. El reconocimiento hecho en 1988 se basó en dichos estudios pero se visitaron sitios de vivienda que no fueron estudiados por C. Scott. Estos comprendieron asentamiento que van desde el Formativo hasta el Horizonte Medio así como aquellos ubicados fuera del valle de Yanamarca. Los métodos fueron simples pero uniformes. Preparamos mapas de los sitios identificados Por Parsons los cuales fueron tomados de las fotografías aéreas. Estos, conjuntamente con las copias de las fichas de sitio, fueron generosamente cedidos por J. Parsons en 1977, año en que se inició el Proyecto de Investigaciones Arqueológicas Alto Mantaro. Esta documentación permitió seleccionar los sitios habitacionales. Se excluyó de los estudios canales, caminos, terrazas agrícolas y cantaras.

Los asentamientos seleccionados fueron luego examinados, evaluando totalmente las condiciones del suelo, densidad alfarera, presencia de estructuras que aún se mantiene en pie, terrazas y derrumbes asociados. También revisamos la existencia de artefactos líticos, incluyendo azadas, formas discoidales y piedras para moler. Utilizamos Transects en zonas con relativa a moderada abundancia de tiestos, calculándose la densidad alfarera en unidades de 4 x $4 \mathrm{~m}$ situados a intervalos de $10 \mathrm{~m}$. En cada área habitacional de $1.5 \mathrm{Ha}$ se proyectó un Transects. Las recolecciones se hicieron a lo largo de estos Transects y en donde la densidad alfarera era alta. El propósito de este procedimiento consistió en calcular la actividad humana en todo el sitio tan precisa como fuera posible para seleccionar sectores de mayor densidad y luego proceder a la colección.

Los Transects se ubicaron mayoritariamente en zonas aradas o recientemente liberadas de sembríos. Los sitios se encuentran en áreas de intenso cultivo y comúnmente se utiliza totalmente o en la forma de mosaicos. Por consiguiente, terrenos con estas características facilitaron la recolección evitándose criterios subjetivos en su ejecución. En los campos agrícolas la recolección se hizo raspando el terreno entre $5-10 \mathrm{~cm}$ de profundidad el cual fue cernido. Denominamos "recolección por raspado" a este procedimiento. El sector de recolección y cernido tiene $3 \mathrm{~m}$ por lado ampliándose hasta obtener una bolsa totalmente llena de tiestos. Se partió de la premisa que una bolsa llena contendría alrededor de 100 tiestos diagnósticos, cantidad que sería suficiente para hacer comparaciones y estimar la cronología del asentamiento. El cernido se hizo en zarandas con malla de $1 / 4$ de pulgada seleccionándose líticos, tiestos cuyas dimensiones sobrepasaban el tamaño del dedo pulgar.

En los sitios que no estaban sometidos a la agricultura, el área habitacional fue examinada mediante excavaciones superficiales, para lo cual se retiró y cernió la capa o zona de humus y raíces (alrededor de $10 \mathrm{~cm}$ de espesor), la misma que proporciona una cantidad similar al procedimiento escrito en el párrafo anterior.

El objetivo consistió en calcular el área habitacional de cada período. Para ello se asumió que un sitio era doméstico si por lo menos con- 
tenía una relativa densidad alfarera (ver Parsons 1976 para definición de términos). Luego el área residencial puede multiplicarse por la densidad calculada del asentamiento (estructura/población por habitante) la cual fue determinada por excavaciones y mapas de los sitios que aún conservan arquitectura (Earle et al. 1987). Este trabajo, que está en marcha, requiere una cronología alfarera elaborada con materiales e excavaciones estratigráficas en Pancán y da una seriación producto de recolecciones de superficie (ver sección cerámica).

\section{III.c Resultados preliminares del reconocimiento (Timothy K. Earle)}

Se examinaron 134 sitios, cantidad que asciende a 160 con los estudiados por Le Blanc en 1978 (Le Blanc 1981). Aún cuando no se ha concluido el análisis de la alfarería y los artefactos líticos, podemos proporcionar resultados preliminares en cuanto se refiere al tamaño de los sitios, ubicación topográfica y cronología. La secuencia ha sido dividida en ocho categorías teniendo en cuenta los tipos alfareros. La más antigua debe aún fecharse con precisión y analizarse estadísticamente para estar seguros de la división alfarera. Las fases son como siguen: Formativo Temprano (Pirwapukio), Formativo Tardío (Cochachongos), Intermedio Temprano (Huacrapukio I), Intermedio Temprano Tardío (Huacrapukio II), Horizonte Medio (Huacrapukio II-III, Wanka O), Intermedio Tardío Temprano (Wanka I), Intermedio Tardío Tardío (Wanka II), Horizonte Tardío (Wanka III) y Colonial Temprano (Wanka IV).

En el cuadro 1 presentamos la cantidad de sitios por período, la cual fue estandarizada multiplicando la cantidad bruta por un factor correctivo que refleja la duración de cada fase. El asentamiento fue disperso durante el Formativo (circa 800-0 AC). Los 4-5 sitios corregidos, identificados para cada fase; son homogéneamente pequeños (a lo mucho unas cuantas has. con más de un vestigio de densidad alfarera). No existen datos sobre jerarquía de asentamientos.
En el Intermedio Temprano (0-600 A.D.) la cantidad de sitios asciende considerablemente a 57. La cantidad exacta es sin embargo difícil de precisar por cuanto dos clases de asentamientos: Huacrapukio indiferenciado con 26 sitios, y San Juan Pata, con 27, no son posibles de ubicar en fase alguna al interior de este período. En consecuencia, 26 sitios se agregan a cada fase no corregida del Intermedio Temprano. El sitio-tipo de San Juan Pata presenta una combinación única de tipos alfareros pero no estamos seguros si este representa una fase más o un tipo de sitio diferente. Además del aumento de sitios en el Intermedio Temprano, también se observa un incremento en la dimensión de los mismos con algunos sitios que sobrepasan las $10 \mathrm{Ha}$. La distribución de los sitios por sus dimensiones sugiere un ranking jerárquico normal. Hasta ahora los asentamientos del Horizonte Medio (600 - 1000 A.D.) no son identificables excepto por la presencia de alfarería Wari, relacionada a Wari o Cajamarca, lo cual es muy raro en las recolecciones. El Horizonte Medio marca un cambio drástico en la alfarería expresada por la división entre Huacrapukio y Wanka. Actualmente el Horizonte Medio debe combinarse con las fases del Intermedio Temprano y el Intermedio Tardío. Al parecer existe una disminución poblacional considerable durante el Intermedio Tardío. Solo se identificaron 53 sitios para las fases Wanka 0-I (800 - 1300 A.D.). Pero los cálculos se aplican únicamente a 26 para la fase corregida aún cuando debido a las observaciones sobre el Horizonte Medio, este cálculo es tentativo. La jerarquía de asentamientos prosigue siendo débil, la mayoría son pequeños pero el crecimiento proporcional de sitios grandes puede indicar la presencia de grupos sociales jerarquizados. Para la fase Wanka II (1300 - 1480 AD), una subdivisión claramente definida mediante excavaciones anteriormente realizadas, la cantidad corregida asciende a 78 , de los cuales muchos son poblados fortificados y aglutinados situados en la cumbre de los cerros. En el norte surgió una nítida jerarquía de sitios con grupos sociales locales distribuidos en por lo menos tres comunidades grandes cada una con dos barios físicamente definidos, plazas centrales y residencias de la elite rodeadas por comunidades más pequeñas (véase Earle et al. 1987 para mayores detalles). El número de sitios aumentó en la fase Wanka 
III del Horizonte Tardío (1480 - 1633 AD), aunque se produjo una reducción del tamaño promedio de los asentamientos. A pesar que las dimensiones fueron diferentes, el tamaño de los centros fueron más pequeños comparados al de la fase anterior, conforme la población local era sometida por los asentamientos del estado Inka.

Son de interés particular varios cambios en los patrones de asentamientos los cuales se asocian a cambios en patrones de la guerra, integración social y en la agricultura. Una manera de observar estos cambios es examinando la frecuencia de los asentamientos asignados a las fases reconocidas y situadas a diferentes altitudes como reflejo del potencial agrícola que exhiben (cuadro 2). Utilizamos tres pisos ecológicos para resumir el potencial agrícola; 3500 metros en donde se concentra el cultivo intensivo, sobre todo maíz; 3600 - 3700 m en donde predomina el cultivo de tubérculos; y $3700 \mathrm{~m}$ en donde el cultivo es cada vez marginal y el potencial de la subsistencia se orienta a la ganadería. Esta división ecológica es igualmente sugestiva con respecto a la seguridad y la defensa si asumimos que a mayor pendiente del terreno mayor preocupación por defenderse; a $<3500$ $\mathrm{m}$ los asentamientos ocupan zonas bajas cerca del piso el valle; a $3500-3700 \mathrm{~m}$. se ubican sobre las laderas y cumbre de los cerros; y a $>3700$ $m$ se hallan en colinas elevadas que hubieran sido defendidas con mayor facilidad. Si examinamos rápidamente el cuadro 2 se constata que los asentamientos se distribuyen en todos los pisos ecológicos, denotando probablemente una economía mixta de agricultura en el valle y las tierras altas, así como pastoreo, a través de la secuencia. Los sitios al parecer ocupan zonas defensivas en todas las épocas, destacando particularmente la fase Wanka II, momento en que los sitios se concentran en colinas elevadas sugiriendo una creciente preocupación por defenderse. Los asentamientos de esta fase son inusualmente grandes y densos construidos con varios muros de fortificación. En cambio, durante la fase Huacrapuquio II la mayor parte de sitios se encuentran en sectores no elevados y sin defensas.

¿Qué causas motivaron el desplazamiento hacia las partes más altas o el retorno al fondo del valle? El desplazamiento a las zonas más elevadas se debió al parecer a presiones entre los asentamientos, a presiones al interior de los mismos y a alianzas políticas, a juzgar por los restos arquitectónicos defensivos (Le Blanc 1981); Earle et al. 1987; Hastorf ms.).

\section{CUADRO 1}

FRECUENCIA DE SITIOS DOMÉSTICOS SEGÚN FASES ALFARERAS

\begin{tabular}{|c|c|c|c|c|}
\hline Fase & No de sitio & $\begin{array}{c}\text { Duración de } \\
\text { fase en Años }\end{array}$ & $\begin{array}{c}\text { Correción } \\
\text { Factor B }\end{array}$ & $\begin{array}{c}\text { Frecuencia } \\
\text { corregida de } \\
\text { sitios }\end{array}$ \\
\hline Pirwapukio & 6 & 400 & .63 & 4 \\
\hline Cochachongos & 8 & 400 & .63 & 5 \\
\hline Huacrapukio I & 69 & 300 & .83 & 57 \\
\hline Huacrapukio II & $70^{a}$ & 300 & .83 & 58 \\
\hline Wanka I & $53^{a}$ & 500 & .50 & 26 \\
\hline Wanka II & 50 & 160 & 1.55 & 78 \\
\hline Wanka III & 69 & 73 & 3.42 & 236 \\
\hline
\end{tabular}

a. Para las fases Huacrapukio I y II se agregaron 26 asentamientos a sus cantidades originales de 43 y 44 respectivamente, con la finalidad de tomar en cuenta 26 sitios Huacrapukio y 27 de San Juan Pata los cuales no fueron asignados a fase particular alguna.

b. El factor de corrección fue determinado al dividir una fase ideal de 250 años por la duración calculada de cada fase. 


\section{CUADRO 2}

CANTIDADES Y PORCENTAJES (EN PARÉNTESIS) DE SITIOS DE VIVIENDA SEGÚN ALTITUD O PISO ECOLÓGICO “A”

\begin{tabular}{|l|c|c|c|}
\hline \multicolumn{1}{|c|}{ Fase } & $3500 \mathrm{~m}$ & $3500-3700 \mathrm{~m}$ & $3700 \mathrm{~m}$ \\
\hline $\begin{array}{l}\text { Período Intermedio } \\
\text { Temprano: }\end{array}$ & & & \\
Huacrapukio I & $19(.50)$ & $15(.39)$ & $04(.11)$ \\
Huacrapukio II & $26(.67)$ & $10(.26)$ & $03(.08)$ \\
Período Intermedio & & & \\
Tardío: & $28(.58)$ & $14(.28)$ & $07(014)$ \\
Wanka I & $22(.44)$ & $13(.27)$ & $14(.29)$ \\
Wanka II & & & $11(.19)$ \\
Horizonte Tardío: & $38(.45)$ & $18(.37)$ & \\
Wanka III & & & \\
\hline
\end{tabular}

“a” Los totales pueden ser inferiores a los del cuadro 1, pues algunos sitios cuya descripción se consigna en el file preliminar no presentan altitudes.

Los asentamientos fortificados han sido generalmente considerados en Perú como evidencia de condiciones inestables y conflictivas. En Huamachuco se han encontrado sitios fortificados pertenecientes a fines del Horizonte Temprano y al Intermedio Temprano (Topic y Topic 1987), igualmente en el Mantaro Inferior (Browman 1970) y en los valles de la costa central y norte (Dagget 1987; Earle 1972; Topic y Topic 1987; Wilson 1987). En general se asume que la guerra es resultado de competencias internas (Dagget 1987, Earle 1978), pero Wilson (1987) propuso que la guerra surge para defenderse de amenazas externas. Asentamientos fortificados del Intermedio Tardío con evidencias de conflicto han sido ampliamente descritos para los Andes centrales y del sur (Hyslop 1976; Le Blanc 1981), Kranowski 1984, Parsons y Hastings 1988). La evidencia histórica apoya igualmente la tesis según la cual la guerra en el Intermedio Tardío fue resultado de competencias internas entre comunidades locales (ver por ejemplo Rowe 1946; Le Blanc 1981).

La ocupación del valle pudo estar influenciada por factores político-económicos externos. Se sabe que el desplazamiento al fondeo del valle durante la fase Wanka III fue oca- sionado por los Inkas, y más tarde, en 1570, por las Reducciones de Toledo (Toledo 1940; D'Altroy 1981). De igual forma, luego de la incorporación del valle del Santa al estado Moche y del valle de Lurín al estado Lima (Wilson 1987, Earle 1972), al parecer devino una paz regional conjuntamente con la mudanza de los asentamientos a lugares sin defensa. ¿Existió también algún factor externo que causó el desplazamiento de la población al propio valle del Mantaro al final del período Intermedio Temprano?

Considerando las tendencias propuestas para otras regiones de los Andes Centrales; el cambio del patrón de asentamiento hacia el valle pudo generarse por influencia de las costa central o Wari, sea económica o políticamente, en la época del Horizonte Medio. Sin embargo, únicamente se encontró alfarería Wari en dos sitios (un tiesto Wari por sitio). La distribución muy dispersa de los artefactos asociada a la inexistencia de la arquitectura Wari en la parte Norte del valle del Mantaro, no sugiere influencia directa Wari. En cualquier caso, debería existir alguna influencia menor responsable del desplazamiento de la población local al propio valle, a juzgar por lo sucedido en otros valles de los Andes Centrales (Isabell 1986). 
Sin embargo, es problemático fechar este asentamiento. Según los estudios estratigráficos en Pancán al cambio del patrón de asentamiento a sectores menos elevados, se produjo en la fase Huacrapukio II, momento en que prácticamente no se encuentran evidencias Wari en el valle. A pesar de la inexistencia de datos sobre el impacto directo Wari en la zona norte del Mantaro, parece probable que los grupos locales establecieron cierta integración regional y estabilidad en esa etapa (Borges 1988). Esto podría ser análogo al cambio a asentamientos no fortificados grandes en Ayacucho, justo antes de la formación del estado Wari (Isabell 1988). Cabe mencionar que los inicios del cambio a la construcción de asentamientos fortificados en las partes altas, una población dispersa y la discontinuidad de los estilos alfareros, así como la aparición de los nuevos rasgos culturales Huanka, puede muy bien corresponder al colapso Wari. Al margen del carácter de la influencia Wari en los Andes, este requiere estudios mucho más profundos.

\section{III.d. Excavaciones en Pancán (Christine Hastorf)}

Este pequeño pueblo agricultor se halla en una de las islas artificiales del borde sureste de la laguna de Paca en donde deviene en manantial. El sitio mide aproximadamente $6 \mathrm{Ha}$. Los vestigios cubren 30 por $60 \mathrm{~m}$ incluyendo una estructura rectangular incaica en el centro. La figura 2 ilustra un mapa topográfico del sitio con las unidades de excavación hechas en 1985. Además del área arqueológica existe un camino artificialmente elevado desde la orilla hasta el propio sitio.

Pancán fue seleccionado debido a las exitosas excavaciones de prueba hechas en dicho asentamiento en 1977 y 1979 (Earle, D'Altroy y Le Blanc 1978; Hastorf 1983). Esas excavaciones registraron una excelente preservación de los vestigios orgánicos y evidencias de cimientos intactos de construcciones. Por las excavaciones sabemos que la ocupación abarca del Intermedio Temprano al Horizonte Tardío, Los fechados para Pancán van de 110 a 1010 AB y se presentan en el cuadro 3; como se constata estas fechas no tienen una secuencia clara. Por eso, aunque proporcionamos todos los fechados no necesariamente creemos que todos son válidos. En cualquier caso, las fechas confirman que el sitio estuvo ocupado antes y durante el Horizonte Medio. La difusa ocupación del Horizonte Tardío en la mitad sur del sitio fue deliberadamente evitada para las excavaciones; de modo que no contamos con fechas asociadas a cerámica Inka.

Las investigaciones se iniciaron mediante reconocimientos magnéticos subsuperficiales con el fin de localizar muros debajo de la superficie. Se tomó información de tres niveles. Observamos notables diferencias en secciones específicas sugiriendo que el sitio era más seco y/o más profundo en el lado norte. Desafortunadamente esta información no proporcionó algo nuevo a lo que ya sabíamos por las trincheras excavadas. El problema fundamental con técnica fue la cercanía del lago y el alto contenido de humedad del suelo, que alteró los valores registrados.

Las excavaciones se situaron en el norte pues sabíamos que el lado sur es menos profundo y contiene depósito inka. Por efectos de la última cosecha y por la rapidez de las excavaciones, consideración tomada a comienzos de la temporada de campo, se excavó un área de 7.5 por $5 \mathrm{~m}$, dejando un borde de 1 metro el cual separa dos excavaciones grandes. Este procedimiento minimizó la extensión de las excavaciones pero fue útil en la distribución espacial de los datos y los cortes para interpretación estratigráfica. La excavación se dividió en áreas arbitrarias de $5 \times 5$ m identificadas de la A hasta la F, cada área fue luego dividida en cuatro unidades de $2.5 \times 2.5 \mathrm{~m}$ identificadas con números del 1 al 4.

Las mediciones horizontales y verticales se tomaron al interior de las áreas y después fueron reajustadas a un datum fijo ubicado a $6 \mathrm{~m}$. al este de la excavación (señalando en las clases BM en la figura 2).

En total excavamos cinco depósitos culturales antes de llegar a la napa freática situada a $2 \mathrm{~m}$. debajo de la superficie. Cada nivel representa un horizonte o estructura mayor, principalmente compuesto de estructuras y patios, dividido a menudo con paredes. El nivel 1 co- 


\section{CUADRO 3}

Fechas RC 14 y Calendarias de Pancán

\begin{tabular}{|c|c|c|c|}
\hline Clave PIAA & $\begin{array}{l}\text { Clave de } \\
\text { Laboratorio }\end{array}$ & $\begin{array}{l}\text { Fecha } \mathrm{RC} 14 \text { no co- } \\
\text { rregida, AP }\end{array}$ & Calibración $\mathrm{AD}$ (a) \\
\hline \multicolumn{4}{|l|}{ Nivel 1: } \\
\hline 76 & Pitt-0239 & $1575 \pm 40$ & $440 \pm 40$ \\
\hline $1-5-5-1$ & I- 12,739 & $1020 \pm 80$ & $10(2 \pm 80(960,1039)$ \\
\hline \multicolumn{4}{|l|}{ Nivel 2: } \\
\hline 343 & QL-4202 & $1070 \pm 40$ & $980 \pm 40(988,1008)$ \\
\hline \multicolumn{4}{|l|}{ Nivel 3: } \\
\hline 422 & Pitt-0240 & $1885 \pm 70$ & $110^{+} .70$ \\
\hline 463 & Pitt-0241 & $1765 \pm 50$ & $250 \pm 50$ \\
\hline 482 & Pitt-0242 & $1495 \pm 35$ & $560 \pm 35$ \\
\hline \multicolumn{4}{|l|}{504} \\
\hline (a) & Pitt-0243 & $1555^{+} .46$ & $635^{+}, 45$ \\
\hline (b) & QL-4203 & $1885^{+}, 40$ & $689^{+}, 40(672,777)$ \\
\hline \multicolumn{4}{|l|}{ Nivel 4: } \\
\hline 622 & Pitt-0244 & $1685^{+}, 35$ & $415^{+}, 35$ \\
\hline $1-1-16-1$ & I- $12-737$ & $1388^{+}, 210$ & $654^{+}, 210(430,880)$ \\
\hline $707 / 708$ & QL-4204 & $1420+-40$ & $637+-40(604-655)$ \\
\hline
\end{tabular}

(a) Basado en la Curva de Stuiver y Pearson (1985: Fig. 1). Las calibraciones con desviación stantard en paréntesis son de Stuiver.

(b) La muestra 504 fue dividida en dos partes.

mienza en la parte superior y así sucesivamente. Descubrimos ocupaciones primarias incluyendo cimientos de viviendas en cuatro de los cinco niveles; niveles $1,3,4$ y 5 . Se registraron adobes en los cinco niveles.

La excavación se hizo siguiendo el sistema matriz de Harris (Harris 1979). Según este sistema cada componente, sea capa o hallazgo, es identificado independientemente, relacionándolos entre sí luego que concluyeron todas las excavaciones y que se obtuvo la mayor cantidad de datos posibles. Esta pequeña unidad culturalmente significativa es denominada por nosotros Locus. Esta se define por el tipo de suelo, su ubicación en el sitio, eventos de deposición tales como cortes o secuencias constructivas. Cada Locus recibió número único de tal suerte que todos los artefactos fueron codificados con relación a su ubicación particular. Esta clasificación permite un manejo rápido y seguro de la información en la computadora. Hicimos mediciones individualizadas de cada Locus que contenía numerosos artefactos.

\section{III.e. Arquitectura (Christine Hastorf)}

A medida que avanzaba la excavación nos encontramos con áreas o patios definidos por cimientos de construcciones que hemos denominado subdivisiones arquitectónicas (SDA), término utilizado anteriormente por nuestro Proyecto (PIAAM) y el cual refiere a una parte de un complejo o área doméstica llamada división arquitectónica (DIVAR) (Earle et al. 1987). 


\section{III.e.1 Nivel 1}

La primera división arquitectónica o complejo doméstico, incluyendo patio y cubriendo toda la excavación del Nivel 1, es la DIVAR 1 ilustrada en la Fig. 3. Puesto que este nivel se ubicaba en la superficie no fue difícil seguir las paredes sin retirar mucho suelo. En consecuencia se pudo extender las excavaciones para descubrir completamente un patio que medía 12 × 9 m de lado. Todas las construcciones tenían una o dos hileras de cimientos de piedra. Algunas exhibían pozos de cimiento al interior de las cuales se colocaron las piedras, pero en otros casos los cimientos se hallaban sobre la superficie nivelada para tal fin. Aplicando el sistema Harris en nuestras excavaciones estamos en condiciones de reconstruir la secuencia constructiva y sugerir qué estructuras fueron contemporáneas.

Descubrimos tres estructuras en el Norte (áreas E y F). Estaban una sobre la otra según se observa en el perfil de la Fig. 4, el cual revela que sus habitantes hicieron las construcciones casi directamente sobre la superficie de la estructura previa. Excavamos primero la SDA 1 (Fig. 3), la cual constituye una estructura circular casi completa con un acceso que da al sur y al patio. Las estructuras inferiores, SDA 2, 3, estaban derruidas y parecían haber sido destruidas por remodelaciones posteriores, excepto en sus bases. Varias de ellas tenían fogones con arcilla roja y concentraciones de basura. Según los datos botánicos los restos de basura eran de naturaleza doméstica y no indicaban actividad especial alguna.

En la sección sur del área excavada había tres estructuras que se asociaban al mismo patio. Estas eran distintas de las otras SDA pues se ubicaban inmediatamente una sobre otra. Por la parte noroeste-sureste del patio, la cual se adosa a dos estructuras circulares grandes, SDA 7, 8, constatamos que estas estructuras grandes se construyeron primero, uniéndose más tarde a ellas la pared del patio. Subsecuentemente, se agregó la pequeña construcción de forma $\mathrm{D}$ que se halla entre ambas. Probablemente esta pequeña SDA 6, es contemporánea con la última estructura norte (SDA 1).
Se han encontrado fogones en el interior de la mayoría de estas estructuras, siendo SDA 7 la mejor conservada. Aparte del piso cuidadosamente elaborado esta construcción exhibía una clara ocupación incluyendo una concentración de quinua (Chenopodium quinoa) en la esquina noroeste cerca a un fogón. En la figura 5 presentamos el perfil estratigráfico sur de esta estructura. La lectura microestratigráfica se observan varios trozos de adobe de la pared que se desprendió del cimiento de piedra.

Descubrimos varias secciones de la pared del patio aunque nunca excavamos los accesos que conducen al propio patio. Este tenía evidencias de diversas actividades, figurando fogones, hoyos y paredes derrumbadas, especialmente adobes calcinados. Estos últimos fueron las primeras evidencias de paredes derrumbadas. En principio creímos que era un Jacal (palos y barro), pero al final de las excavaciones recuperamos evidencias según las cuales las estructuras Sausa se componen de adobes colocados sobre bases de piedra y por consiguiente concluimos que los restos de adobe encontrados en el patio provienen del propio patio o las paredes.

Fuera del patio y al oeste, excavamos una porción de otro patio el mismo que estaba cubierto con artefactos (tiestos y líticos). Esta característica, distinta a la superficie con gravas de la DIVAR 1, sugiere que las áreas abiertas del patio fueron deliberadamente cubiertas para formar las superficies.

\section{III.e.2. Nivel 2}

El segundo nivel no contenía evidencias de cimientos de piedras ni complejos de patio. El nivel fue profundo, de 40-60 cm. Los depósitos se componían de materiales amorfos de arcilla y sedimentos con grava en acequias y capas delgadas a modo de lentes, predominando por trozos de adobe cascajoso. Había basura dispersa, hoyos y elementos raros como depresiones circulares delineadas con arcilla de color blanquecino, la cual contenía varios trozos de arcilla de colores diferentes. 
Nuestra hipótesis sobre las actividades culturales de este nivel es que las estructuras habitacionales más permanentes se ubicaban ligeramente fuera del área excavada. Esto se refuerza por los perfiles Este y Oeste los cuales presenta restos de paredes de adobe asociados con basura, un patrón identificado en patios posteriores. Otro componente común a este nivel y a los más profundos, es la superficie irregular de cantos rodados. No registramos funciones claras para estos elementos pero lo más probable es que se asocian al drenaje de la humedad o quizá como medios para facilitar el desplazamiento en un área fangosa.

Puesto que se documentaron sólo algunos loci, este nivel es uno de los más difíciles de interpretar. La evidencia continua y esporádica de actividades sugiere que los habitantes vivían en las inmediaciones. Otra alternativa es que en esta época el sitio estuvo desocupado, pero esporádicamente visitado.

Dicho uso podría corresponder con un desplazamiento del sitio hacia la colina durante el colapso Wari. La única fecha $\mathrm{Rc}^{14}$ del nivel 2 es aproximadamente 980 AD (cuadro 3).

\section{III.e.3. Nivel 3}

Este nivel contenía un patio con dos estructuras circulares grandes (SDA 12, 12), una pequeña estructura redonda (SDA 11) y un espacio abierto o patio, el cual constituye DIVAR 4 (Fig. 8). En el interior del patio había un semicírculo pequeño compuesto de una hilada de piedra que hace curva desde la estructura 13. Esto quiere decir que el patio se dividió por áreas para distintos usos. Ambas estructuras grandes proporcionaron buenas evidencias de paredes de adobes, con trozos de pared sobre y debajo de los pisos. En base a lo excavado parece que ambas estructuras tenían 5 metros de extensión, una significativa diferencia frete a la dimensión de $3.2 \mathrm{~m}$ del nivel 1 . Por esta razón no se pudo excavar gran parte del patio de la misma forma como se hizo en el nivel 1.

La estructura o SDA 12, del lado norte es particularmente importante. El depósito revela que las tres estructuras de este patio estuvieron quemadas, pero la № 12 exhibía un piso totalmente calcinado y con abundantes restos botánicos carbonizados. Probablemente esta construcción se utilizaba para guardar productos de la cosecha doméstica. Disperso sobre el piso y mezclado con trozos de madera había restos de quinua, tarwi, (Lupinus mutabilis), oca (Oxalis tuberosa), papas (Solanum tuberosum) y maíz (Zea mays). Consideramos que estos productos se almacenaron en recipientes orgánicos, susceptibles de quemar, los cuales o iban colgados de las vigas del techo o de la pared. Aparentemente el fuego vino del norte a juzgar por 1 dirección del viento de hoy en día. Al arder la estructura los productos cayeron al piso. La construcción no parece que volvió a utilizarse. La pared de adobes se derrumbó y junto con el desmonte quemado creó la mejor parte del nivel 2. El piso de la estructura (SDA) 12 tenía hoyos que se rellenaron con materiales producto del incendio. Este depósito sugiere que algunos de los hoyos estaban vacíos al momento de incendio. Un hoyo estaba previamente rellenado con fragmentos grandes de alfarería tipo Huacrapukio (Fig. 8). Las otras estructuras (o SDA $12,13)$ fueron abandonadas antes pues había algunos artefactos en los pisos. Sin embargo, la pequeña SDA 11 tiene evidencias de hierbabuena, un arbusto empleado pata almacenar productos agrícolas, así como mayor cantidad de madera en comparación a las otras estructuras, sugiriendo que se trataba de una estructura para almacenamiento.

\section{III. e. 4. Nivel 4}

Casi directamente debajo de las SDA 12 y 13 fueron identificadas las SDA 16 y 17 del nivel 4 respectivamente (DIVAR 6, Fig. 7).

La pared de adobes caída fue nivelada entre estas estructuras. Ambas (13 y 17) contienen información sobre una modalidad arquitectónica de los niveles más profundos. Ambos se construyeron sobre un círculo de cantos rodados pequeños. Sobre éstos se colocó un cimiento de piedras grandes, y luego sobre éste se hallan adobes grandes con impresiones de grass o pasto. Los adobes fueron unidos con piedras pequeñas y arcilla gris pura directamente aplicada en ambos lados de la pared. 
A pesar que la mayoría de rasgos de la SDA 17 estaban destruidas, había un fogón intacto en el piso así como concentraciones de restos botánicos descubiertos durante el proceso de flotamiento.

La SDA 16 fue aún más extraña según puede constatarse por el plano de la fig. 7. Aunque encontramos la parte exterior del cimiento, no se pudo definir con claridad el borde sur. Registramos varias paredes pequeñas de adobe al interior de la estructura. La SDA 16 norte es verdaderamente una gran parte del patio, creando un recinto que luego se dividió en varias subdivisiones pequeñas y modificables, o estas pequeñas paredes dividían una estructura grande. La evidencia demostrando funciones domésticas a la estructura 16 proviene del fogón descubierto en la esquina noreste, característica similar a la observada en estructuras posteriores. La base de este nivel estuvo extraordinariamente húmeda, apareciendo la napa freática en la sección inferior de los muros.

La SDA 16 constituye el segundo tipo de construcción mayor presente en los niveles inferiores. No se observan cimientos hechos con piedras pequeñas, y más bien las paredes exhiben piedras grandes unidas con arcilla. Se utilizaron piedras de tamaños diferentes para hacer las paredes, las mismas que debieron transportarse desde las canteras situadas alrededor del lago (comunicación personal de Seltzer en 1988). Inmediatamente encima de estas piedras encontramos fragmentos de adobes.

\section{III. e.5. Nivel 5}

Fue excavado mediante una serie de trincheras exploratorias debajo de las estructuras y del patio pertenecientes al nivel 4. Puesto que la mayor parte de este nivel se hallaba por debajo de la napa freática fue necesario utilizar una bomba extractora de agua de 3 caballos de fuerza para observar la estratificación. Se pudo observar que debajo de la pared norte correspondiente a la SDA 16, existía otro cimiento grande hecho de piedras. También confirmó la excavación de la totalidad del cuarto nivel y la presencia de un nivel de ocupación más temprano. El material del nivel 6 fue extrema- damente duro, con tiestos especialmente grandes. Este hallazgo sugiere que sus ocupantes lo cubrieron rápidamente construyendo el patio de la DIVAR 8, sellando así la deposición cultural previa. Según la trinchera más profunda se sabe que hubo otra ocupación $50 \mathrm{~cm}$ debajo de la superficie del patio perteneciente al nivel 4. El material del nivel 5 es parte de esta ocupación más profunda.

\section{III. e.6. Trinchera 1}

Una de la trincheras de 2 por $2 \mathrm{~m}$ excavadas en 1987 sirvió de guía a nuestras excavaciones, y nos permitió observar la parte inferior de nuestras excavaciones en 1988. Nuestras excavaciones se ubicaron alrededor de esta trinchera 1, para aprovechar sus perfiles y las evidencias de estructuras como guía de los trabajos realizados en 1986. Luego de llegar a la napa freática utilizamos la bomba extractora para retirar el agua de la trinchera y continuar profundizando en una sección de la misma. El objetivo consistió en conocer la profundidad real del depósito cultural y la secuencia continuada desde Usupukio a comienzos del Intermedio Temprano, el cual cambia al estilo Huacrapukio en el nivel 5. En consecuencia considerando la cerámica, los niveles 4,3 y 2 de las excavaciones de 1986 corresponden a la parte final del Intermedio Temprano, Horizonte Medio, Huacrapukio II y Wanka C; en cambio el nivel 1 se asigna a la fase Wanka I del Intermedio Tardío (ver secuencia).

\section{III. f. Análisis de los materiales}

\section{III.f.1 Cerámica}

\section{(Lisa Le Count)}

El propósito de los estudios alfareros hechos en 1988 fue desarrollar una cronología regional del Alto Mantaro utilizando materiales excavados de Pancán y tiestos de superficie de parte norte del valle (cuadro 4). La cerámica de Pancán se utiliza en la construcción de una secuencia alfarera la cual puede compararse al material de superficie como complemento de aquellos períodos y regiones no representados 


\section{CUADRO 4}

\begin{tabular}{|c|c|c|c|}
\hline Fechas* & Periodos & Fase & Tipos diagnósticos \\
\hline $\begin{array}{l}1534 \\
1460\end{array}$ & $\begin{array}{l}\text { Horizonte } \\
\text { Tardío }\end{array}$ & Wanka III & Tipos Inka y todo Wanka II \\
\hline 1300 & $\begin{array}{l}\text { Intermedio } \\
\text { Tardío }\end{array}$ & Wanka II & $\begin{array}{l}\text { Wanka Rojo } \\
\text { Engobe micáceo } \\
\text { Base Roja } \\
\text { Base Claro }\end{array}$ \\
\hline \multirow[b]{2}{*}{$\begin{array}{l}200 \\
600\end{array}$} & \multirow[b]{2}{*}{$\begin{array}{l}\text { Horizonte } \\
\text { Medio }\end{array}$} & Wanka I & $\begin{array}{l}\text { Base Clara } \\
\text { Alfar grueso con mica } \\
\text { Wanka engobe Púrpura } \\
\text { Wanka Púrpura sobre naranja sin engobe } \\
\text { Wanka Púrpura sobre claro } \\
\text { Wanka Claro sobre rojo }\end{array}$ \\
\hline & & $\begin{array}{l}\text { Huacrapukio } \\
\text { II }\end{array}$ & $\begin{array}{l}\text { Huacrapukio Púrpura sobre naranja } \\
\text { Tipos Huacrapukio } \\
\text { Wanka Púrpura sobre engobe naranja }\end{array}$ \\
\hline \multirow{3}{*}{$\begin{array}{l}200 \\
0 \mathrm{AC}\end{array}$} & \multirow{2}{*}{$\begin{array}{l}\text { Intermedio } \\
\text { Temprano }\end{array}$} & $\begin{array}{c}\text { Huacrapukio } \\
\text { I }\end{array}$ & $\begin{array}{l}\text { Huacrapukio Púrpura sobre naranja } \\
\text { Tipos Huacrapukio } \\
\text { Alfarería de Pasta Rosada }\end{array}$ \\
\hline & & & $\begin{array}{l}\text { Pulido con guijarro } \\
\text { Engobe crema }\end{array}$ \\
\hline & Formativo & $\begin{array}{l}\text { Tardío } \\
\text { Medio } \\
\text { Temprano }\end{array}$ & $\begin{array}{l}\text { Cochachongos } \\
\text { Pirwapukio }\end{array}$ \\
\hline
\end{tabular}

(*) Fecha aproximada.

en Pancán. Aunque el material excavado de Pancán solo ha sido fechado hasta mediados del Intermedio Temprano (Huacrapukio II) y muchos de los sitios contienen materiales de fases diferentes, se elaboró una seriación provisional la misma que deberá revisarse en el futuro (Owen, Borges y Le Count 1988). Aparte de definir una cronología regional la alfarería recuperada en 1986 sirve de base para el estudio de las actividades sociopolíticas y económicas de esta área (Borges 1988, LeCount 1987).

\section{III.f.1.a. Sobre la Seriación}

Los tipos alfareros se definieron considerando la composición de la pasta, tratamiento de la superficie y los elementos estilísticos generales. Los alfareros se definieron como tipos particulares de pasta y temperante conjuntamente con estilo, entendido este último como la combinación de motivos estilísticos y diseño morfológico. El tratamiento de superficie se define por la pintura, engobe, color de la pasta y acabado. En consecuencia, estilo, alfar y tratamiento de superficie se combinan entre sí para definir un tipo. Consideramos este procedimiento como el sistema de clasificación más adecuado (Apéndice 1).

La seriación de la alfarería de Pancán proporciona ciertos tipos diagnósticos para las fases Wanka I y Huacrapukio II, aunque el Horizonte Medio incluyó ambos conjuntos. En total encontramos seis tiestos Wari y parecidos a Wari (tres para cada grupo) en los niveles 2 y 3. Además, parece que no existe influencia del estilo Wari en la cerámica local.

Huacrapukio I se definió por la alta frecuencia de alfarería de pasta rosada asociada con cerámica estilo Huacrapukio encontrada en las colecciones de superficie. Huacrapukio I es estilísticamente equivalente y contemporánea a las fases Uchupas Tardío y Usupukio de Browman (1970: 127-132-133) definidos 
para el sur del valle. La parte más temprana del Intermedio Temprano ha sido difícil definir en el Norte del valle del Mantaro. Los materiales que se asignarían a los inicios de este período se encontraron en sitios con varias fases de ocupación y contienen pequeñas cantidades de tipos diagnóstico que serían temporal y localmente particulares. En consecuencia esta fase inicial permanecerá pobremente definida hasta que se realicen más excavaciones. La fase tardía del Formativo esta representada por un tipo de diagnóstico conocido y definido por Browman (1970:115) con el nombre de Cochachongos. Los sitios que proporcionaron cuencos estilo Cochachongos tenían también otros tipos ninguno de los cuales pudo asociarse definitivamente al conjunto del Formativo Tardío. El componente más temprano conocido en el norte del río Mantaro presenta cerámica Pirwapukio según la definición de Drowman (1970:105). Este aparece en sitios de una sola ocupación.

\section{III. f.1.b. Descripción de los tipos diagnósticos}

Pirwapukio es el único componente del Formativo Temprano. El alfar marrón compuesto por varias cantidades de inclusiones sedimentarias y micáceas, exhibe superficies cuidadosamente pulidas con guijarro las cuales pueden mostrar engobe rojo o negro, incisiones, patrón bruñido o diseños negativos circulares y simples. Las formas son principalmente cuencos simples.

Al igual que en la parte sur del valle, el estilo Cochachongos del Formativo Tardío tiene un tratamiento de superficie particular compuesto por Cheurones, "alfabetos" y bandas lineales cerca y en el exterior del borde de cuencos (Fig. 8 a, b). Estos cuencos altamente pulidos exhiben tratamientos de superficie bicromos o policromos de color rojo, negro o naranja sobre claro sin engobe. En el norte del Mantaro este estilo se aplica por los menos tipos de parte y temperante. Jarras con engobe crema, pulidas sin cuidado con guijarro, o jaras globulares llanas con inclusiones gruesas sub-angulares se asocian a estos cuencos, los cuales continúan fabricándose en el Intermedio Temprano.
El estilo Huacrapukio es el grupo principal de las fases Huacrapukio I, II. Se le ubica en pequeños porcentajes en la fase Wanka I. En las fases Huacrapukio (Intermedio Temprano y Horizonte Medio) el característico labio grueso y doblado presente en jarras y el motivo púrpura sobre naranja compuesto por líneas que penden de bandas lineales u ondulantes situadas cerca del borde, se asocian con por lo menos seis alfares (Fig. 8 d, e). El estilo Huacrapukio utilizó igualmente modelados toscos aplicados alrededor del cuello de las jarras así como figuras modeladas de animales situadas en el cuello de dichos recipientes. En ambas fases encontramos representaciones de camélidos en gestación y figuras humanas. También se le encuentra desde las fases Usupurkio hasta Calpish propuestas por Browman para el sur del Mantaro (Browman 1970:79-139). Esta extensa y duradera tradición alfarera indicaría intensas afiliaciones culturales regionales entre los pobladores de esta zona (Arnold 1985; Balfet 1965; Rice 1981).

La fase Huacrapukio I contiene por lo menos $10 \%$ de pasta rosada, una forma típica de cuenco abierto con paredes delgadas, pequeñas cantidades de temperante fino, superficies exteriores pulidas con guijarro, motivos pintados de púrpura en el interior (Fig. 8 c). Otros dos tipos de pasta, naranja y ceniza, presentan propiedades físicas y estilísticas similares. Los motivos sobre la pasta rosada son difíciles de describir por lo erosionado de la superficie, constituyendo los elementos más característicos en ambas fases del estilo Huacrapukio. Aunque deberán hacerse análisis estilísticos cuantitativos de estos alfares, se puede adelantar que los diseños más tempranos exhiben camélidos y bandas en el interior de la mayoría de cuencos. Estos derivan hasta formar bandas de sieño situadas cerca del borde interior.

El elemento diagnóstico de Huacrapukio II es la presencia de tipos tempranos Wanka en combinación con cuencos de pasta rosada y alfarería Huacrapukio. Los tipos tempranos del estilo Wanka llevan el característico estilo que identifica a las modalidades más tardías llamadas Sase Clara y Wanka Rojo, pero también exhiben pintura púrpura sobre engobe naranja de manera semejante al Huacrapukio Inicial o Temprano. 
La presencia de Huacrapukio es menor en la fase Wanka I (Fig. 8: f, g). La cantidad de tiestos pintados también es menor. En Pancán el 52\% de la alfarería Wanka I es llana, en comparación al 11\% de tiestos llanos correspondientes a la fase Huacrapukio II (Borges 1988:15). Asociado a simplificación del estilo encontramos únicamente tres alfares.

Los tipos Wanka I difieren en dos aspectos de los tipos Wanka Más tardíos. Primero, el color predominantes púrpura (Wanka I) es reemplazado por el color negro (Wanka II, III); los engobes de varios colores empleados en la fase Wanka I, se reduce a rojo y crema en las fases posteriores. Segundo, al alfar predominante de la fase Wanka I contiene inclusiones de origen sedimentario en gran proporción, mientras que más tarde el temperante se compone de cantidades moderadas tipo caliza. La reducción paulatina de la complejidad estilística, engobe, cantidad de áreas pintadas y alfares desde Huacrapukio hasta las fases tardías del estilo Wanka, indicaría la existencia de alfareros a tiempo parcial.

Huanca II y III fueron intensamente estudiados por otros investigadores (Le Blanc 1981); D'Altroy 1981; Costin 1986), de manera que presentaremos descripciones de ambas fases. Sin embargo, parece evidente que el componente Wanka II o se originó o tiene antecedente en la fase previa. La característica típica de la fase Wanka III es la incorporación de tipos Inka, a los componentes básicos que distinguen al Wanka II.

Basándose en esta cronología, Borges (1988) intentó definir la interacción Wari en el valle teniendo en cuenta la presencia de cerámica Wari, cambios en los patrones de asentamiento al constatarse que las fases Huacrapukio II y Wanka I de los sitios Calpis y Wariwilka de la parte sur del Mantaro, tenían claras correspondencias con los complejos alfareros de la parte norte del valle.

Le Count (1987) utilizó alfarería de Pancán y excavó previamente los sitios Wanka II y III para investigar cambios en la organización sociopolítica y económica de los Sausa. El complejo de cuencos pertenecientes a la fase Huacrapukio II está representado prepon- derantemente por recipientes pequeños para servir, incrementándose luego tanto en cantidad como en complejidad hasta la fase Wanka III, denotando un continuo crecimiento en la magnitud y frecuencia de actividades sociales y públicas auspiciadas por familias de la élite para establecer alianzas, comodidad y prestigio asociados a funciones políticas. Las jarras expresan estabilidad desde la fase Huacrapukio II hasta Wanka II, reflejando ello pocos cambios en la preparación de alimentos y el almacenamiento.

\section{III. f. 2. Artefactos Líticos}

\section{(Slenn Russell)}

La temporada de campo realizadas en 1986 proporcionó cerca de 1200 artefactos líticos, provenientes de reconocimientos de superficie del cernido y de las muestras sometidas a flotamiento. Mientras estuvimos en Perú se hizo un análisis preliminar tecnológico y funcional. El inventario total incluyó herramientas trabajadas a percusión y piedra para moler. $\mathrm{Al}$ respecto, merece destacar los contrastes entre los depósitos tardíos y tempranos de Pancán y éstos a su vez con los correspondientes a las fases Wanka II y III.

Si consideramos las frecuencias y proporciones de los materiales tallados a percusión y aquellos empleados para moler, desde el nivel 1 hasta el nivel 4 de Pancán, se observan algunas tendencias (cuadro 5). A pesar que los ejemplos para Pancán son escasos, existe una ligera disminución en la importancia de los bifases (puntas) a través del tiempo, de $1.0 \%$ a $0.1 \%$. Simultáneamente se produce un aumento en la frecuencia de otros artefactos dedicadas a la subsistencia. Por ejemplo las azadas no aparecen en el nivel 4, pero aumentan consistentemente hasta alcanzar el $13.3 \%$ de los materiales líticos pertenecientes al nivel 1 .

La proporción de todas las herramientas sobre láminas utilizadas y sin utilizar aumenta de nivel 4 al nivel 1, indicando el uso cada vez más frecuentes de estas herramientas a través del tiempo. Es interesante anotar que las lascas disminuyan quizá como reflejo de la depen- 


\section{CUADRO 5}

Artefactos líticos tallados y Para moler de Pancán en CANTidades y PORCentaje. EsTOS ÚLTIMOS PROVIENEN DEL TOTAL DE ARTEFACTOS POR NIVEL

\begin{tabular}{|c|c|c|c|c|c|c|c|c|}
\hline \multirow[t]{2}{*}{ FORMAS } & Nivel & 1 & Nivel & 2 & Nivel & 3 & Nivel & 4 \\
\hline & Cant. & $\%$ & Cant. & $\%$ & Cant. & $\%$ & Cant. & $\%$ \\
\hline Lascas no utilizadas & 1973 & 74.2 & 1698 & 83.3 & 1072 & 80.2 & 303 & 74.8 \\
\hline desechos de talla & 38 & 1.4 & 49 & 2.4 & 50 & 3.8 & 14 & 3.5 \\
\hline núcleos & 77 & 2.9 & 29 & 1.4 & 112 & 8.2 & 62 & 15.3 \\
\hline cuchillo sobre lasca & 56 & 2.1 & 21 & 1.0 & 12 & 0.2 & 4 & 1.0 \\
\hline raspadores sobre lasca & 30 & 1.1 & 12 & 0.5 & 10 & 0.8 & 4 & 1.0 \\
\hline perforador discoidal & 1 & 0.1 & 0 & 0 & 0 & 0 & 0 & 0 \\
\hline bifaces (puntas) & 3 & 0.1 & 5 & 0.2 & 7 & 0.5 & 4 & 1.0 \\
\hline unifaciales & 15 & 0.6 & 7 & 0.3 & 23 & 1.7 & 8 & 2.0 \\
\hline denticulados & 1 & 0.1 & 3 & 0.1 & 1 & 0.1 & 0 & 0 \\
\hline perforador retocado & 17 & 0.6 & 10 & 0.5 & 2 & 0.2 & 1 & 0.2 \\
\hline muesca & 0 & 0 & 0 & 0 & 2 & 0.2 & 0 & 0.5 \\
\hline choppers & 9 & 0.3 & 3 & 0.1 & 1 & 0.1 & 2 & 0 \\
\hline unifaciales sobre & 0 & 0 & 0 & 0 & 1 & 0.1 & 0 & 0 \\
\hline núcleo & 5 & 0.2 & 2 & 0.1 & 0 & 0 & 0 & 0.7 \\
\hline hachas & 36 & 1.4 & 13 & 0.6 & 5 & 0.4 & 3 & 0 \\
\hline láminas no utilizadas & 0 & 0 & 0 & 0 & 1 & 0.1 & 0 & 0 \\
\hline núcleo para láminas & 18 & 0.7 & 7 & 0.3 & 5 & 0.4 & 0 & 0 \\
\hline cuchillo sobre láminas & 4 & 0.2 & 8 & 0.3 & 0 & 0 & 0 & 0 \\
\hline "hoz" sobre lasca & 5 & 0.2 & 3 & 0.1 & 2 & 0.2 & 0 & 0 \\
\hline "hoz” sobre lámina & 354 & 13.3 & 158 & 7.8 & 19 & 1.4 & 0 & 0 \\
\hline fragmentos de azada & 3 & 0.1 & 2 & 0.1 & 0 & 0 & 0 & 0 \\
\hline $\begin{array}{l}\text { material para azada } \\
\text { sin identificar }\end{array}$ & 1 & 0.1 & 2 & 0.1 & 0 & 0 & 0 & 0 \\
\hline TOT A L & 2660 & & 2036 & & 1325 & & 405 & \\
\hline
\end{tabular}

\begin{tabular}{|c|c|c|c|c|c|c|c|c|}
\hline \multirow[t]{2}{*}{ MOLEDORAS } & Nivel & 1 & Nivel & 2 & Nivel & 3 & Nivel & 4 \\
\hline & Cant. & $\%$ & Cant. & $\%$ & Cant. & $\%$ & Cant. & $\%$ \\
\hline manos & 2 & 2.9 & 1 & 2.5 & 4 & 6.6 & 1 & 2.8 \\
\hline moledoras & 2 & 2.9 & 3 & 7.5 & 12 & 14.0 & 9 & 25.0 \\
\hline batanes & 1 & 1.4 & 5 & 12.5 & 11 & 12.8 & 4 & 11.1 \\
\hline trituradoras & 18 & 26.4 & 6 & 15.0 & 8 & 9.3 & 1 & 2.8 \\
\hline morteros & 5 & 7.4 & 1 & 2.5 & 5 & 5.8 & 0 & 0 \\
\hline abrasivos & 1 & 1.5 & 1 & 2.5 & 0 & 0 & 0 & 0 \\
\hline sin identificar & 15 & 22.1 & 14 & 35.0 & 17 & 19.8 & 3 & 8.3 \\
\hline piedras & 16 & 25.5 & 5 & 12.5 & 10 & 11.6 & 5 & 13.9 \\
\hline piedras con agujeros & 1 & 1.4 & 1 & 2.5 & 2 & 2.3 & 0 & 0 \\
\hline discos perforados & 7 & 10.3 & 3 & 7.5 & 17 & 19.8 & 13 & 36.1 \\
\hline T O T A L & 68 & & 40 & & 86 & & 36 & \\
\hline
\end{tabular}


dencia cada vez mayor en herramientas sobre láminas para cortar. Las herramientas para moler también presentan patrones interesantes. La cantidad de discos perforados disminuyen desde el nivel 4 hasta la parte superior de Pancán. Moledoras y baterías también disminuyen desde el nivel 4 hasta el nivel 1.

En conjunto el aumento de frecuencia más notable de Pancán es en las azadas. Aunque la mayor parte del inventario lítico no varió demasiado y los depósitos continuaban mostrando una presencia estándar de herramientas domésticas, la inexistencia de azadas en los niveles más profundos indica que el cultivo con azada fue prácticamente regular sólo a partir de la fase Wanka I. Además de la tecnología lítica sobre núcleos y lascas, se fabricaron herramientas prismáticas laminares, sobre todo durante la ocupación Wanka I. Estas láminas proceden de núcleos preparados y con toda probabilidad fueron utilizadas para cortar y segar plantas, esto último inferido por el alto brillo que deja el contacto con los silicatos.

Existen algunas diferencias marcadas entre las herramientas de Pancán y las recuperadas en otros sitios correspondientes a las fases Wanka II-III. Quizá lo más frecuente de Pancán es el uso de lascas para cortar y la ausencia de láminas, las cuales aparecen en sitios tardíos. A diferencia de las herramientas tardías se encuentra mayor silicato en las lascas más no en las láminas de Pancán.

La lámina prismática de la cantera local de Pomacancha (Russell 1988) es el artefacto predominante de los depósitos Wanka II-III. Estos siempre exhiben brillo de silicato y probablemente se insertaban en un mango de madera siendo utilizadas a modo de "hoz" simple. Se fabricaban en lugares especializados y eran objeto de intercambio con otros asentamientos. A pesar que en Pancán encontramos láminas su frecuencia fue exigua con respecto a la identificación en sitios tardíos, sobre todo en contextos Wanka II. No identificamos evidencias de fabricación de láminas en Pancán.

Las herramientas para moler incluyen piedras para triturar y discos perforados hechos en rocas volcánicas granulosas y en bloques planos de "phyllite". El utillaje para moler comprende manos, batanes, moledoras hemisféricas, morteros, trituradores esféricos, trituradores oblongos, piedras para trabajo de abrasión y formas discoidales perforadas. Los hoyos de éstas últimas presentan alto pulimento por desgaste. Disminuyen significativamente en cantidad absoluta en los niveles 1 y 2 , implicando un cambio de las herramientas sea para la guerra o en la tecnología agrícola. Las formas básicas de las piedras de moler no exhiben cambios a través de la secuencia, aunque sí se notan variaciones en sus frecuencias relativas. Las moledoras también disminuyen, de 39\% a 3\%. En Pancán es mayor la frecuencia de morteros y chancadores, mientras que en sitios más tardíos predominan batanes y moledoras de mayores dimensiones (Russell 1988).

Las herramientas bifaciales de Pancán no aparecen en sitios tardíos. En Pancán existe una variedad de puntos triangulares, bases cóncavas y ovoides. Si bien estos artefactos son escasos (una docena) se nota a través de la secuencia una evidente disminución de las mismas. Prácticamente no existen en sitios Wanka II-III y los recuperados fueron al parecer retrabajados o proceden de épocas más tempranas.

A pesar que la obsidiana fue un componente menor de la industria lítica, su frecuencia en Pancán fue mayor comparada a la de sitio Wanka II-III, la cual sugiere que el intercambio de la obsidiana disminuyó considerablemente. Por sus características químicas casi toda la obsidiana proviene de la cantera de Quispisisa, Huancavelica, $100 \mathrm{~km}$ al sur.

Las azadas son abundantes en los niveles superiores de Pancán, sobre todo en la fase Wanka III. La figura 9 contiene frecuencias de superficie y de excavaciones, con unidades ajustadas por volumen de suelo. Luego del Horizonte Medio la mayor frecuencia de azadas se correlaciona a un patrón de asentamiento orientado al fondeo del valle. Se podría inferir a partir de esta distribución que este tipo de herramienta agrícola tendió a utilizarse en zonas no elevadas, probablemente para remover los suelos arcillosos fértiles. Se podría también sugerir que las azadas se asocian al cultivo del maíz por la correspondencia entre las frecuencias de azadas y maíz a lo largo de la secuencia, 
pero esto es muy tentativo. Antes de Wanka I y II cuando estos instrumentos no eran comunes, las herramientas agrícolas alternativas pudieron ser palos puntiagudos para cerrar y quizá artefactos de forma discoidal, en lugar de azadas adheridas a maderas o palos largos.

El intercambio de materias primas líticas no fue común. La población tendió a utilizar las canteras locales, y por ello se ha encontrado una amplia variedad de materias primas en sitios en el fondo del valle del Mantaro, cerca de los depósitos ribereños. Únicamente la obsidiana se obtenía en pequeña proporción, en otros lugares extraños al Mantaro.

\section{III. f. 3 Metales (Christine Hastorf)}

Encontramos 43 objetos de metal en el transcurso de las excavaciones; 3 fueron recogidas en los reconocimientos. El inventario original fue completado por Bruce Owen. Puesto que los provenientes de la superficie adolecen de contextos, la descripción que sigue se concentrará en los excavados (cuadro 6). La densidad de los objetos aumentó a través de la secuencia. Se han identificado dos piezas de oro, un oro de fabricación serrana (comunicación personal de B. Owen, 1986) y una aguja, ambos del nivel 2. También en este mismo nivel se registró un fragmento de plata, cuya fabricación puede ser local. El resto de objetos son de cobre y son de manufactura igualmente local. Estos últimos comprenden agujas, tupus, aros, láminas, formas alargadas con o sin cabezas circulares, discos y otros no definidos. El metal se presenta en diversos contextos sobre todo en los pisos de las estructuras, en los patios, en derrumbes de paredes y rellenos, en tumbas y basura. Gran parte de las agujas y tupus están dobladas o rotas sugiriendo que fueron deliberadamente rotas o convertidas en prendedores simples. Las cabezas de numerosos tupus fueron rotas y el extremo resultante fue torcido.

Las siete piezas encontradas en el nivel 4 son de cobre y provienen de contextos funerarios e incluyen piezas alargadas y tupus. En un solo entierro había cuatro objetos. En el nivel 3 encontramos 9 piezas. Dos alargadas y un adorno proceden de las estructuras 12 y 13 y otras dos aparecieron en el patio asociado a dichas construcciones. Las cinco piezas restantes fueron principalmente formas alargadas registradas en los derrumbes de las paredes y en el relleno. En el nivel 2 se recuperaron 12 formas alargadas y agujas en depósitos compuestos por paredes derrumbadas y basura. Es en este nivel donde encontramos, en la basura, las tres piezas de oro. La distribución de los metales del nivel 1 es muy semejante a la del nivel 3 . De los 15 fragmentos de cobre, un disco y un tupu provienen del piso de las estructuras 1 y 7 respectivamente. Tres objetos fueron encontrados en un patio de piedras situado en la parte occidental del patio central. Dos se hallaron en el patio entre estas estructuras circulares y el resto en la capa agrícola sometida al arado y en desmonte reciente.

Aunque se han encontrado tupus (decorativos y utilitarios) en todos los niveles, éstos son más frecuentes en las zonas de ocupación del nivel 1. En el nivel 2 las agujas son más abundantes (utilitarias). Esta distribución sugiere que los pobladores de Pancán descartaron o perdieron ocasionalmente el metal mientras trabajaban en el exterior de la unidad doméstica, hecho sumamente raro en las áreas habitadas.

\section{III. f. 4. Restos Botánicos (Christine Hastorf)}

Hemos recogido aproximadamente 1200 muestras de suelo. De cada locus provienen dos muestras que pesan 6 kilos cada una, las cuales fueron luego sometidas a la técnica de flotamiento utilizando un sistema motorizado de bombeo de agua diseñado originalmente por Paty Jo Watson (1976). Este sistema consiste en mantener el agua circulando en un recipiente para que los restos botánicos se desprendan de la tierra con el menor daño posible y afloren a la superficie del agua por ser menos pesados. Puesto que el suministro de agua es constante ésta va descartándose a través de un ducto. A su vez el material que va aflorando se traslada cuidadosamente a pequeños cernidores usados en geología (cuyas mallas tienen de $0.5 \mathrm{~mm}$ a $6.35 \mathrm{~mm}$ ). Luego son transferi- 


\section{CUADRO 6}

Metales encontrados en Pancán

\begin{tabular}{|c|c|c|c|c|c|c|c|c|}
\hline Nivel & Tupu & Aro & Lámina & $\begin{array}{c}\text { Forma } \\
\text { alargada }\end{array}$ & Disco & Aguja & $\begin{array}{c}\text { № } \\
\text { Ident. }\end{array}$ & Total \\
\hline 1 & 7 & 0 & 0 & 4 & 1 & 1 & 2 & 15 \\
2 & 2 & 1 & 3 & 2 & 0 & 3 & 1 & 12 \\
3 & 0 & 0 & 2 & 4 & 0 & 1 & 2 & 9 \\
4 & 4 & 0 & 0 & 3 & 0 & 0 & 0 & 7 \\
\hline
\end{tabular}

dos o colocadas sobre trozos de tela auxiliados con un spray fino para agua. Luego de secadas, son pesadas y embaladas para su estudio en el laboratorio. Mediante este procedimiento obtuvimos una muestra "ligera" y otra "pesada", ésta última compuesta por materiales que afloraron a la superficie, todas como restos de plantas adheridas al suelo, rocas, líticos, huesos, cerámica, etc. Estos fueron clasificados en el campo con la ayuda de cerdineras finas procurando conservar restos pequeños tales como vértebras de pescado, residuo de metal, etc. También hubo algunos restos de plantas en la muestra "pesada".

Este sistema proporciona muestras botánicas comparativas de toda la excavación, además es igualmente importante al producir muestras que puedan compararse a otras previamente preparadas para el Alto Mantaro. En otras palabras, ofrece una estrategia de micromuestreo de todas las clases de vestigios, recobrando artefactos cuyas dimensiones sobrepasan los $0.5 \mathrm{~mm}$.

La estrategia de muestreo aplicada en Pancán es particularmente relevante. Los paleoetnobotánicos discuten desde hace tiempo varios procedimientos y en general se han utilizado dos técnicas: muestras grandes provenientes de un solo contexto y muestras dispersas pequeñas. Puesto que existe controversia sobre la idoneidad de dichas técnicas, ambas fueron utilizadas en Pancán. Luego del análisis éstas serán comparadas. Una muestra por cada técnica fue recuperada en todas las unidades excavadas. Incidentalmente cuando se identificaron evidencias de actividades especiales tales como fogones o actividades en los pisos, se recogieron muestras grandes adicionales. Puesto que se cernió el 100\% del suelo excavado, también encontramos restos botánicos en los cernidores cuyas mallas tenían orificios de $1 / 4$ de pulgada.

Los restos identificados comprenden la totalidad de cultivos andinos: maíz (Zea mays L.), Talhui (Lupinus mutabilis Dulce), Quinoa (Chenopodium quinoa Silvestre), papas (Solanum rosu Loz.) y mashua (Tropaeolum tuberosum L y P). Mientras que estas plantas se observan en toda la secuencia, son los cambios en sus frecuencias que nos darán información sobre patrones culturales. Actualmente, la microzona alrededor de Pancán produce todas estas plantas, pero es especialmente ideal para el maíz, situación que no se presenta en muchas áreas de los andes. También se encuentra en proceso la identificación de árboles, al término de la cual se harán las comparaciones correspondientes con las curvas polínicas para las orillas de la laguna Paca. El cuadro 7 presenta una visión general de los porcentajes de las especies de plantas procedentes de 7 ó 3 muestras pertenecientes a los cuatro niveles de Pancán, las cuales fueron analizadas por Heidi Lennstrem en el laboratorio de Arqueobotánica de la Universidad de Minnesota. Los porcentajes indican una visión general de la presencia de flora en Pancán, esta se expresa calculando la cantidad de muestras que pertenecen a una clase específica, sin considerar necesariamente las frecuencias de las plantas. Por ejemplo, la presencia del $50 \%$ de maíz significa que el $50 \%$ de las muestras analizadas tienen uno o más especímenes de dicho cultígeno. Este procedimiento permite observar las distintas especies independientemente de las otras. Hasta el momento notamos un incremento en la frecuencia del maíz a través del tiempo, en cambio el Chenopodium y los tubérculos permanecen estables. Las leguminosas domésticas parecen disminuir a comienzos del Horizonte Medio. 


\section{CUADRO 7}

Presencia porcentual de plantas domesticadas por niveles en Pancán

\begin{tabular}{|c|c|c|c|c|c|}
\hline Nivel & $\begin{array}{c}\text { Cantidad } \\
\text { de muestras } \\
\text { analizadas }\end{array}$ & $\begin{array}{c}\text { Zea mays } \\
\text { (maíz) }\end{array}$ & Chenopodium & $\begin{array}{c}\text { Leguminosas } \\
\text { domesticadas }\end{array}$ & tubérculos \\
\hline 1 & 265 & 94 & 95 & 33 & 7 \\
2 & 131 & 97 & 95 & 32 & 8 \\
3 & 157 & 86 & 93 & 10 & 10 \\
4 & 150 & 51 & 89 & 5 & 6 \\
\hline
\end{tabular}

\section{III. f.5. Fauna}

(Elsie Sandefur)

La utilización de fauna se expresa por cerca de 38000 fragmentos de hueso procedentes de un total de 800 loci (capas o elementos especiales) excavados en Pancán. Los huesos de animales fueron encontrados en las zarandas (mallas de $1 / 4$ y $1 / 8$ de pulgada) y en las muestras de suelo para flotamiento. Todos los huesos que se excavaron en 1986 han sido identificados, a excepción de los fragmentos diminutos encontrados en las muestras "ligeras" producto del flotamiento.

La predominancia de camélidos es evidente (cuadro 8). También son comunes huesos de cuy (Cavia parcellus), recuperamos por lo menos un hueso de cuy en cada capa. Huesos de perro son raros pero existen en los dos niveles superiores. Algunos dientes de vicuña (Viguna Vicugna) sugieren que este camélido era cazado en la fase Wanka I; fragmentos de hueso y hasta de venado indican que la taruga (Hippocamelus antisonsis) y probablemente el venado de cola blanca (Codoncailous virginianus) eran también cazados.

Teniendo en cuanta las mediciones propuestas por Elizabeth Wing (1972) para identificar camélidos, las cifras indican que la llama es predominante en los depósitos culturales. Se asume que fue utilizada principalmente como bestia de carga y para la alimentación. La alpaca (Lama pacos) es más frecuente en el nivel 2 y probablemente sirvió para obtener lana.

La escasez de huesos es explicable por un ambiente asociado a lago. Aves, ranas y peces están débilmente representados tanto en las zarandas de malla gruesa como en las finas, y en las muestras para flotamiento (colectivamente sumada "micro" en el cuadro 8). Encontramos huesos de ave, por ejemplo el pato americano (Fulica americana), Ayno (Pulica ordesiaca), pato de la puna (Amas flavirostris) y de una falcónida no identificada. La rana de Junín (Batrachophrynus macrostomus) aparece en menor proporción conjuntamente con restos de una especie pequeña de batracio. Se encontró una gran cantidad de vértebras de pescado pero pocos los huesos de pescado son escasos, sobre todo en los niveles inferiores (comunicación personal de M. Lerstrom).

Los artefactos óseos son más numerosos en los niveles superiores (Wanka I) sugiriendo la existencia de depósitos con mayor concentración de artefactos en fases tardías. Es necesario comparar los artefactos óseos con los líticos a fin de entender totalmente los cambios en el uso de los mismos, aunque se nota el incremento de herramientas para cortar en los niveles tardíos. Huesos calcinados y cortados también se concentran en estos niveles (cuadro 8). El creciente cambio en los huesos modificados refleja una utilización más compleja de los animales, por lo menos en contextos domésticos.

"La indicación más clara de tratamiento especial, consideración que por ello se asume, es el entierro de un animal" (Wing 1968; 262). Los huesos de animal encontrados en Pancán comprendió no solo artefactos óseos, basura y otros vestigios, sino también esqueletos completos y articulados de camélidos y cuyes enterrados en cestas claramente definidos. Las tumbas de 39 animales diferentes se ubicaron principalmente en los patios y se concentraron en los niveles tempranos más profundos (Fig. 16). La edad establecida por la erupción y desgaste dental y la fusión de la epífisis en los huesos largos indican que todos los camélidos 
fueron sacrificados a la edad de seis a nueve meses y que la mayoría de cuyes fueron también jóvenes.

\section{III. f.6. Moluscos (Christine Hastorf)}

Encontramos solamente 12 fragmentos de moluscos, incluyendo dos de la especie Spondylus. $\mathrm{Su}$ escasez sugiere que el intercambio entre lugares distantes para obtener moluscos marinos no era común para los habitantes de Pancán. Es notable a través de la secuencia de Sausa, la existencia de escasa información sobre intercambio entre otros lugares distantes.

\section{III. f.7 Entierros (Christine Hastorf)}

Se recuperaron 18 entierros en Pancán. Ninguno estaba en buen estado de conservación por lo cual fue imposible excavar un esqueleto completo. Todos estaban en hoyos o cestas simples, de poca profundidad o fosas profundas en forma de $\mathrm{L}$ con mayor espacio en el fondo. A pesar que el análisis es parcial, a excepción de dos individuos, todos fueron adultos. En un solo hoyo encontramos dos niños y dos adultos. Los cadáveres estaban flexionados y de costado, con el rostro orientado frecuentemente al norte. Únicamente un adulto más o menos flexionado yacía directamente en el piso de la estructura 16. Cinco cadáveres fueron depositados en fosas en forma de L, algunas de las cuales se profundizaron más allá de las excavaciones realizadas en 1986.

No se recuperaron ofrendas en todas las tumbas figurando recipientes pequeños de arcilla y husos de tejer como los objetos más comunes. Solamente 2 entierros del nivel 4 tuvieron ofrendas de metal. Quizá lo más notable de estos entierros es que aparecen exclusivamente en los niveles $2,3,4$. Semejante a la distribución de los metales esta diferencia señala cambios en las prácticas mortuorias desde el Intermedio Temprano hasta el Intermedio Tardío. Los entierros de los niveles tempranos se hacían en hoyos profundos excavados en los recintos. Posteriormente en la fase Wanka I los entierros aparecen en otros sectores, apartados de la actividad diaria.

\section{Discusión (Christine Hastorf)}

Los reconocimientos realizados en 1986 se basaron en estudios regionales previos. Las investigaciones en Pancán ofrecen el primer contexto de excavaciones orientadas a cubrir el lapso entre el Intermedio Temprano y el Intermedio Tardío de la región jaujina. Desde el punto de vista arquitectónico se identificó continuidad y cambio a través de la secuencia regional.

Las estructuras formativas de la zona (Browman 1970; Matos 1973; comunicación personal de S. García Soto 1986) presentan adobes rectangulares con superficies blanco-lechosas que alcanzan hasta $4.5 \mathrm{~m}$ de amplitud.

En Pancán encontramos estructuras circulares pertenecientes al Intermedio Temprano, alcanzando hasta $6 \mathrm{~m}$ de diámetro. Los adobes fueron colocados sobre cimientos de piedra con mortero de barro que sobrepasaba en ancho a la pared de adobes. Estos cimientos fueron de forma irregular traídos de canteras locales. Se encontraron restos de una mezcla arcillosa blanco-lechosa los cuales sugieren que algunas paredes fueron enlucidas; otras paredes de adobe fueron cubiertas con una fina capa de arcilla gris. Los pisos a su vez presentan un sedimento amarillo fino por sobre los cimientos de los edificios. Los entierros de seres humanos y animales tienden a concentrarse debajo del piso de los patios.

Los patios del Intermedio Temprano-Horizonte Medio de la zona norte del Mantaro son espaciosos y al parecer no tuvieron paredes que los circundan totalmente. Arquitectónicamente no podemos describir los sitios ubicados sobre las colinas y correspondientes a fines del Intermedio Temprano, excepto señalar que algunos sitios tenían paredes de piedra que los circundan y que las estructuras fueron hechas con roca caliza local. 
Las estructuras Wanka I - Intermedio Tardío son más pequeñas, con $3 \mathrm{~mm}$ de diámetro promedio, existiendo en cambio mayor número de estructuras asociadas a un patio. El espacio del patio también parece ser más pequeño y cercado. También, la construcción de los pisos de los recintos no demandó mayor esfuerzo. Por otro lado, los hoyos tan frecuentes en fases tempranas disminuyen considerablemente. Al mudarse la población a las partes altas del valle en la fase Wanka II, las estructuras se construyeron a base de paredes o pirka de doble cara, para lo cual las piedras se extraían del propio lugar. Los patios Wanka II siempre están cercados y exhiben escasas evidencias de pisos construidos deliberadamente. Este tipo de patio continúo construyéndose en Wanka III, mostrando cierta influencia del estilo Inka por las estructuras rectangulares.

A pesar que la arquitectura cambió a través del tiempo, parece que la organización y utilización del espacio doméstico permaneció estable. Por este dato podemos inferir que la población fue el mismo grupo cultural a través de la secuencia. En general, los complejos de patio fueron utilizados de la misma forma. Los fogones prosiguieron siendo simples y se les encuentra en las estructuras y en los patios, ubicándose de modo casual en distintas secciones de las estructuras señaladas. Existe más de un fogón por complejo de patio.

Las estructuras sugieren también que fueron hechas en tiempos diferentes al interior del ciclo o lapso en que estuvo en uso el complejo de patio. Los restos de basura se concentran mayormente hacia el patio y las paredes divisorias internas, así como en las secciones que separan las estructuras. Los entierros de seres humanos se localizan en los recintos, patios, a veces se superponen, y en áreas de múltiples actividades.

Por los datos arquitectónicos consideramos que cuando describimos un patio cercado, nos referimos a áreas domésticas (Wilk and Rathje 1982). En este caso, un área doméstica es una unidad social autosuficiente productiva y reproductivamente, aunque puede constituirse más de una familia nuclear cuyos miembros pueden desplazarse a más de un lugar. Pero en la unidad social donde se satisfacen todas las necesidades en donde se produce la mayor cantidad de objetos y en donde se obtienen los recursos. En este sentido parece tratarse de un fenómeno social estable renuente a cambios estructurales, aún cuando puede cambiar su propia composición.

Los reconocimientos y las excavaciones permiten proponer preliminarmente que los Sausa cambiaron política y económicamente a través de la secuencia. Si bien la unidad doméstica era la unidad social, es evidente que los pobladores se consagraban en determinadas épocas - desplazándose en grupos grandes a nuevos asentamientos - dispersándose en otras épocas. Los artefactos sugieren también cambios en los patrones agrícolas y alimenticios. Esto indicaría que las desigualdades sociales se volvieron más pronunciadas generando decisiones de más alto nivel sobre asuntos políticos, congregando, mudando el asentamiento o uniéndose a otras comunidades. La estructura sociopolítica mayor pudo afectar las decisiones económicas asumidas por la unidad doméstica, así como también al vecindario y población.

En el periodo Formativo la población se asentó cerca de manantiales pequeños, situados en áreas protegidas y productivas, desde donde se podía dominar el paisaje circundante. Este patrón prosiguió durante el Intermedio Temprano a medida que surgían nuevos poblados y ocupaban las márgenes del valle. La población pudo disminuir al mudarse a lugares protegidos y fortificados naturalmente. No sabemos hasta la fecha si estos fueron ocupaciones permanentes o zonas temporales de defensa. Estos sitios requieren estudiarse. El cambio en el patrón de asentamientos producido en algún momento a fines de Intermedio Temprano revela que por lo menos una parte de la población fundó nuevos asentamientos en el piso del valle.

En la fase Wanka I notamos por primera vez la ocupación cada vez mayor del valle expresada por el uso de azadas para la agricultura. Probablemente la intensificación de la agricultura es mayor a los períodos previos, acompañada además con arado y remoción más profunda de suelos arcillosos fértiles. Tanto los datos de superficie como las excavaciones de Pancán sugieren que los sitios son ligeramente más gran- 
des en esta fase, los complejos domésticos son más densos y aglutinados, la alfarería es más diversa aunque su producción se sucede en zonas más restringidas. Las vasijas de Pancán son más grandes debido tal vez a que los complejos residenciales se componen de un mayor número de personas. Los datos de Wanka I sugieren que la población había iniciado cambios en su organización social y política internas con alianzas claramente demarcadas. Estos cambios, observados en la producción y los asentamientos, se expresan en los cambios drásticos observados en el período siguiente, Wanka II.

En la época Wanka II del Intermedio Tardío la población no solo se mudó a las partes altas y menos accesibles, sino también se fusionaron varios grupos que estuvieron previamente separados. La reestructuración de los Sausa es también observable en los líticos: son notables nuevas tecnología para obtener láminas y para procesar los cultivos. Las azadas son menos comunes y se aplican tecnologías agrícolas nuevas apropiadas para las tierras altas (canales y terrazas con paredes de piedra (Hastorff 1983). A comparación de los períodos anteriores, la alfarería fue hecha con descuido, los diseños son menos codificados y las dimensiones son menores. Se pueden identificar puntos específicos de producción así como esferas restringidas de intercambio de cerámica (Costin 1986).

Después de la conquista Inka, la población se reubicó otra vez en el valle formando núcleos pequeños. Sabemos que la producción local doméstica cambió sobre todo en los items que el Inka tenía interés: metales, maíz, vestidos, y ciertos tipos de cerámica Inka. Los efectos de la conquista Inka se observan en muchos aspectos de los artefactos de Sausa así como en cambios del patrón de asentamiento (Earle et al. 1987). Se encontró alfarería Inka e imitaciones de la misma en todos los asentamientos (D'Altroy 1981). ¿Se observaría un impacto similar si la zona hubiera sido conquistada antes por los Wari?

En total solamente recuperamos en Pancán tres tiestos Wari y otros tres que se le parecían (hubo contextos excelentes únicamente en la parte superior del nivel 3), y dos de una superficie, sugiriendo que los Wari no tuvieron influencia material directa sobre esta región. Probablemente el cambio en los patrones de asentamiento es atribuible a la presión del colapso Wari, pero hasta el momento no se han recuperado datos arquitectónicos que indiquen presión directa de los Wari sobre Sausa. La mejor indicación del imperio Wari se expresaría en la producción y su acceso a la misma. Discutiremos este punto en otra monografía.

La impresión que tenemos a partir de los datos recogidos es el intenso desarrollo cíclico o más bien en especial, liderazgo político interno, reflejado en la construcción de los Sausa en áreas protegidas y menos productivas, dispersándose luego. Aunque la concentración sucedió dos veces ésta no fue repetitiva, en la medida que nuevas fuerzas políticas y alianzas surgían con cada nueva fase cultural. Estas reflexiones serán repensadas y refinadas conforme se avance con el análisis.

A pesar que es necesario estudiar aún más las fases tempranas, logramos identificar influencias políticas y sociales con los datos expuestos en este artículo. Debemos profundizar nuestros estudios sobre el Formativo y los comienzos del Intermedio Temprano, para entender cómo se insertaron los Sausa en el sistema pan-andino Temprano (Matos 1972). Fechar los sitios y establecer las actividades sucedidas en los mismos, son también otras tareas que nos ayudarán a identificar las causas de estos cambios políticos, sociales y económicos así como sus consecuencias en las unidades domésticas. Parece que estos acontecimientos políticos se originaron al margen de las unidades domésticas sin llegar a reestructurarlas. Sin embargo, debieron afectarlas. Es imposible ignorar las costumbres locales de hoy en día, sobre todo en la región Sausa, en la que el núcleo doméstico familiar es sumamente fuerte al interior de los barrios, indicando que sigue siendo la unidad de producción y reproducción principal, no obstantes las nuevas y permanentes presiones internas y externas.

\section{Agradecimientos}

Este proyecto pudo realizarse gracias al apoyo de numerosas personas, sobre todo de los funcionarios del Instituto Nacional de Cultura quienes prestaron su colaboración durante los 
trámites del permiso (Resolución Suprema № 110-86-ED). Agradezco especialmente al Dr. Francisco Iriarte, al Dr. Fernando Silva Santisteban y a la Dra. Araníbar de Beraún. De igual modo al Dr. Ramiro Matos Mendieta y a la familia Paredes. En Jauja expreso mi agradecimiento a Andrés Moya, José Moya, Ever Moya, Juan de la Cruz, David de la Cruz, Jorge Neyra, Víctor Esteban, Eudolfo Aquino, Pascual Rojas, Egdelberto Flores, Teodoro Marticorena, Ruth Casas, Percy Casas, Héctor Moya, Doris Anchiraico y Edgar Flores.

Participaron también Kim Borges, Cathy Costin, Ken Decker, Timothy Earle, Rubén García Soto, Diana Greenles, Christine Hastorf, Ian Hodder, Timothy Kane, Lisa Le Count, Reidi Lennstrom, Danke Leonar, Bruce Owen, Glenn Russell, Elsie Sandefur, James Snead, Carmen Thays Delgado y Marcus Woodburn.

Igualmente, el equipo geológico estuvo bajo la dirección de Herbert E. Wright Jr. Quien recibió la ayuda de Geoffrey Saltzer y Carrie Patterson. Para la edición contamos con el auxilio de Kathleen.

El proyecto estuvo financiado por la Fundación Nacional de la Ciencia (BNS 84-51369), la Sociedad Geográfica de EE.UU. y el Senado Académico de UCLA con fondos adicionales para redactar los informes de parte del Centro para Estudios Avanzados en Ciencias de la Conducta (BNS 84-11738). Heidi Lennstrom participó con una beca doctoral de la Fundación Fulbright.

\section{Bibliografía}

Arnold, Dean E.

1985 Ceramic theory and cultural process. Cambrigde University Press, Cambridge.

Balfet, Helene

1965 "Ethnographical observations in North Africa and archaeological interpretation". In Ceramics and man, ed. F.R. Watson, pp 161-177. Aldine, Chicago.

Borges, Kimberly A.

1988 Political organization in the Upper Mantaro Valley during the Middle Horizon. M. A. Thesis, Archaeology Program, UCLA.

Browman, David L.
1970 Early Peruvian peasants: the cultural history of a central highlands valley. Unpublished dissertation, Department of Anthropology, Harvard University.

Browman, David L.

1974 "Pastoral nomadisn in the Andes". Current Anthropology 15:188-196.

Costin, Cathy L.

1986 From chiefdom to empire state: ceramic economy among the prehispanic Wanka of highland Peru. PhD dissertation, Department of Anthropology, UCLA. Ann Arbor: University Microfilms International.

Daggett, Richard

1987 "Toward the development of the state on the north central coast of Peru". In the origins and development of the Andean state, ed. Haas, S. Pozorski, and T. Pozorski, pp. 70-82. Cambridge University Press, Cambridge.

Browman, David L.

1974 "Pastoral nomadisn in the Andes". Current Anthropology 15:188-196.

Costin, Cathy L.

1986 From chiefdom to empire state: ceramic economy among the prehispanic Wanka of highland Peru. PhD dissertation, Department of Anthropology, UCLA. Ann Arbor: University Microfilms International.

Earle, Timothy K.

1972 "Lurin Valley, Peru: Early Intermediate Period settlement development". American Antiquity 37: 467-477.

Earle, Timothy K., Terence D'Altroy, and Catherine J. LeBlanc

1978 Regional archaeology of the late prehispanic periods in the Upper Mantaro. Report en the 1977 field season submitted to the Institute Nacional de Cultura, Lima.

Earle, Timothy K., Terence D'Altroy, Catherine LeBlanc, Christine Hastorf, and Terry LeVine

1980 "Changing settlement patterns in the Upper Mantaro Valley, Peru preliminary report for the 1977, 1978 and 1979 seasons of the Upper Mantaro Archaeological Research Project". Journal of New World Archaeology 4(1): 1-49.

Earle, Timothy K., Terence D'Altroy, Christine Hastorf, Catherine J. Scott, Cathy Costin, Glenn Russell, and Elsie Sandefur

1987 Report of the 1982 and 1983 field research of the Upper Mantaro Archaeological Research Project: the effects of Inka conquest on the Wanka domestic economy. Institute of Archaeology, Los Angeles. 
Earle, Timothy K., Christine A. Hastorf, Catherine J. LeBlanc, and Terence D'Altroy

1980 Preliminary report of the 1979 field season of the Upper Mantaro Archaeological Research Project, submitted to the Instituto Nacional de Cultura, Lima.

Flores E., Isabel

1959 "El sitio arqueológico de Wari Willca, Huancayo". Actas y trabajos del II congreso nacional de Historia del Perú: época Prehispánica 2:177-186, Lima.

Fung P., Rosa

1959 "Informe preliminar de las excavaciones efectuadas en el abrigo rocoso № 1 de Tschopik". Actas y trabajos del II Congreso Nacional de Historia del Perú: época Prehispánica 2:253-273, Lima.

Guillet, David

1981 "Agrarian ecology and present production in the central Andes". Mountain Research and Development 1:1:19-28.

Harris, Edward

1979 Principles of archaeological stratigraphy. Academic Press, New York.

Hastorf Christine A.

1983 Prehistoric agricultural intensification and political development in the Jauja region of Central Peru. PhD dissertation, Department of Anthropology, UCLA. Ann Arbor: University Microfilms Internacional.

n.d "One path to the heights: negotiating political inequality in the Sausa of Peru". In The evolution of political systems, ed. S. Uphma, Proceedings from an advanced seminar at the School of American Research, Santa Fe.

Hayden, Brian and Aubrey Cannon

1982 "The corporate group as an archaeological unit". Journal of Anthropological Archaeology 1:132-158.

Hyslop, John

1976 An archaeological investigation of the Lupaca Kingdom and its origin. PhD dissertation, Anthropology, Columbia University, Ann Arbor, University Microfilms International.

Isbell, William

1986 "Huari provincial organization: a preliminary formulation". Paper presented at the Annual Meeting of the Society for American Archaeology, New Orleans.

1988 City and state in Middle Horizon Huari, In Peruvian prehistory, ed. R. Keatinge, pp. 164-189, Cambridge University Press, Cambridge.
Kranowski, Andrezej

1984 Prehistoria andyjskiej doliny. (with english abstract by P. Mizia). Pssolinskich Wydawnictwo Polskiej Akademi, Warsaw.

Leblanc, Catherine J.

1981 Late prehispanic Huanca settlement patterns in the Yanamarca Valley, Peru. PhD dissertation, Department of Anthropology, UCLA. Ann Arbor: University Microfilms International.

LeCount, Lisa

1987 Towards defining and explaining functional variation in Sausa ceramics from the Upper Mantaro Valley, Peru. N.A. Thesis, Department of Anthropology, UCLA.

Lumbreras, Luis G.

1957 "La cultura Wanka". Ondas Isabelinas Órgano de la Gran Unidad Escolar Santa Isabel de Huancayo. 233:15-18.

1959 "Esquema arqueológico de la sierra central del Perú". Revista del Museo Nacional 28: 84-177, Lima.

Matos Mendieta, Ramiro

1959 "Los Wanka, datos históricos y arqueológicos". Actas y trabajos del II congreso nacional de Historia del Perú: época prehispánica 2:187-210, Lima.

1966 "La economía durante el período de reinos y confederaciones en Mantaro, Perú". Actas y memorias del 36 congreso internacional de Americanistas 2:95-99.

1972 "Ataura: un centro Chavín en el Valle del Mantaro". Revista del Museo Nacional 41:37-80, Lima.

Matos M., R. and J. Parsons

1979 "Poblamiento prehispánico en la cuenca del Mantaro". En Arqueología Peruana, ed. R. Matos, pp. 157-171, Lima.

\section{Mayer, Enrique}

1979 Land use in the Andes: Ecology and agriculture in the Mantaro Valley of Peru with special reference to potatoes. International Potato Center, Lima.

Netting, Robert, Richard Wilk, and E. Arnold

1984 Households. University of California Press, Berkeley.

Owen, Bruce, Kimberly Borger, and Lisa Le Count

1988 "Seriation of the 1985 ceramic material from the site of Pancan and survery surface collections. Unpublished manuscript on file in the Upper Mantaro". Archaeological Research Project Laboratory, UCLA. 
Parsons, Jeffrey

1976 "Prehispanic settlement patterns in the Upper Mantaro Valley, Peru". Preliminary report submitted to U.S. National Science Foundation, Washington, D.C.

Parsons, Jeffrey and Charles Hastings

1988 "The later Intermediate Period". In Peruvian Prehistory, ed. R. Keatinge, pp. 190. 228, Cambrigde University Press.Cambrigde.

Parsons, J. and R. Matos M.

1978 "Asentamientos prehispánicos en el Mantaro, Perú: informe preliminar. In El hombre y la cultura andina". Actas y trabajos del III congreso peruano del hombre y la cultura andina, ed. R. Matos, pp. 539. 555. Universidad Nacional Mayor de San Marcos, Lima.

Pulgar Vidal, Javier

1967 Geografía del Perú: Las ocho regiones naturales del Perú. Editorial Universo, Lima.

Rice, Prudence

1981 "Evolution of specialized pottery production: a trial model". Current Anthropology 22 (3): 219-240.

Rowe, John

1946 "Inca culture at the time of spanish conquest". In Handbook of South American Indians, vol 2, ed. J. Steward, pp. 183-330., BAE Bulletin 143, Smithsonian Institution, Washington D.C.

Russell, Glenn

1988 The impact of Inka policy on the domestic economy of the Wanka in the central highlands of Peru: Stone tool production and use. $\mathrm{PhD}$ dissertation, Department of Anthropology, UCLA.

Seltzer, Geoffrey

1987 Glacial history and climatic change in the central Peruvian Andes. MA thesis, Department of Geology, University of Minnesota, Minneapolis.

Stuiver, Minze and G.W. Peterson

1986 "High precision calibration of the radiocarbon time scale, AD 1950-500 BC". Radiocarbon 28 (2) 8: 805-838.

Stuiver, Minze and P. J. Reimer

1987 University of Washington quaternary isotope lab radiocarbon calibration program 1987. University of Washington, Seattle.

Toledo, Don Francisco de

1940 (1570) Información hecha por orden de Don Francisco de Toledo en su visita de las provincias del Perú, en la que declaran indios ancianos obre el derecho de los caciques y sobre el gobierno que tenían aquellos pueblos antes que los Incas conquistasen, in Don Francisco de Toledo, Supremo organizador del Perú. Edited by R. Levillier, Buenos Aires.

Topic, Jhon and Teresa Topic

1987 "The archaeological investigation of Andean militarism: some cautionary observations". In The origins and development of the Andean state, ed. Haas, S. Pozorski, and T. Pozorski, pp, 47-55. Cambrigde University Press, Cambrigde.

Watson, Patty Jo

1976 "In Pursuit of prehistoric subsistence: a comparative account of some contemporary flotation techniques". Midcontinent Journal of Archaeology 1:77-100.

Wilk, Richard and William Rathje

1982 "Archaeology of the household: building a prehistory of domestic life". American Behavioral Scientist 25:617-838.

Wilson, David

1987 "Reconstructing patterns of early warfare in the lower Santa Valley: new data on the role of conflict in the origins of complex north-coast society". In The origins and development of the Andean state, ed. Haas, S. Pozorski, and T. Pozorski, pp. 56-59. Cambridge University Press, Cambridge.

Wing, Elizabeth S.

1972 "Utilization of animal resources in the Peruvian Andes". In Andes 4: excavations at Kotosh, Peru 1963 and 1966. Eds. S. Izumi and K. Terada, pp. 327-351, University of Tokyo Press, Tokyo.

Wing, Elizabeth S.

1986 "Domestication of Andean mammals". High altitude tropical biogeography ed. Francois Vuilleumier and Maximina Monasterio pp. 246-264, Oxford University Press, Oxford.

Wright, H. E., Jr.

1980 "Environmental history of the Junin Plain and the nearby mountains". In Prehistoric hunters of the high Andes. J. Rick. New York: Academic Press, pp. 235-256.

1984 "Late Glacial and late Holocene moraine in the Cerros Cuchpanga, central Peru". Quaternary Research 21:275-285. 


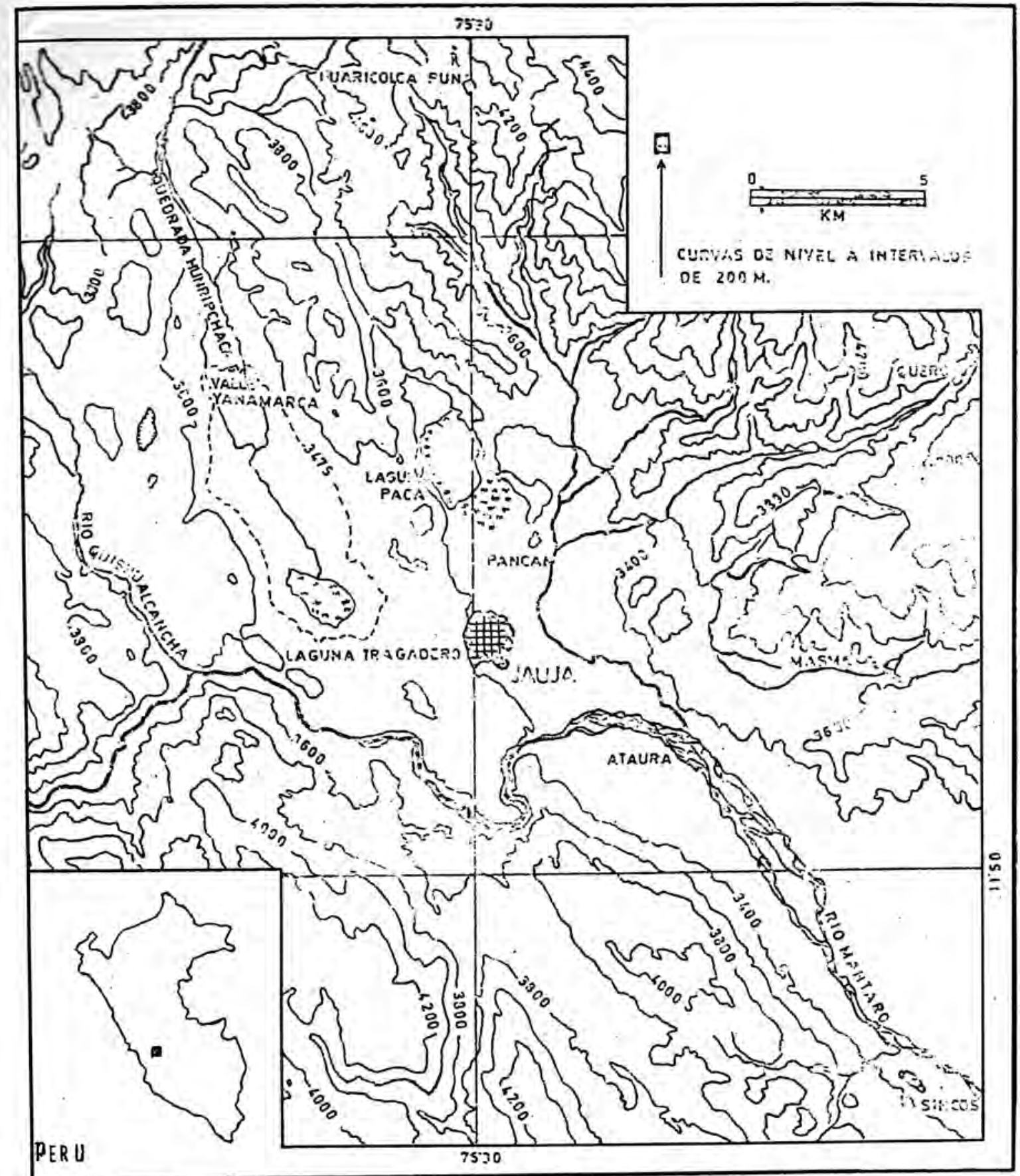

FIG. 1: Jauja, area estudiada. 


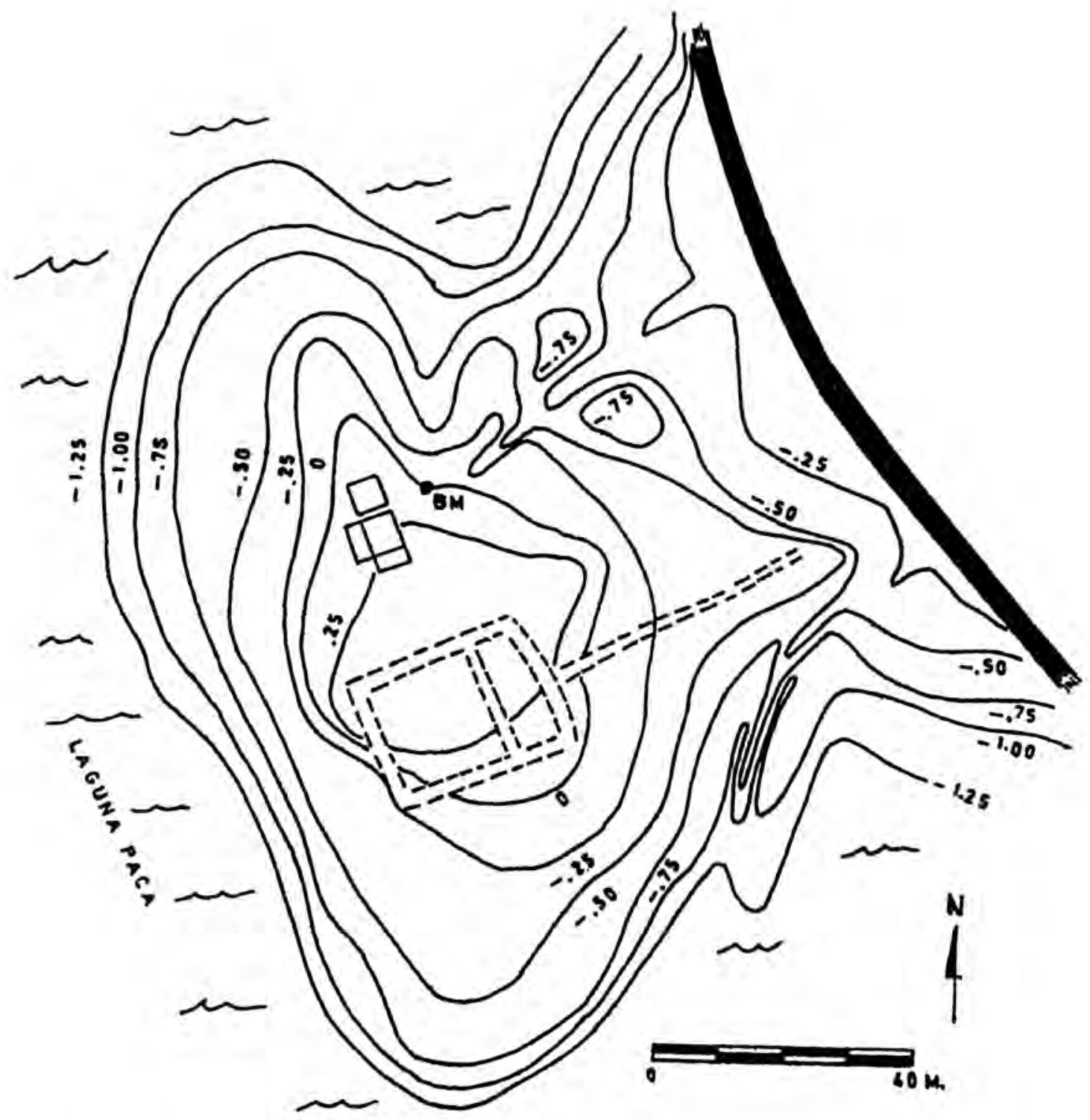

FIG. 2: PANCAN

BM OATUM

-- EstauctuRa INKA

- CARRETERA

ए ExcAYACIONES

น

La GUNA PACA 

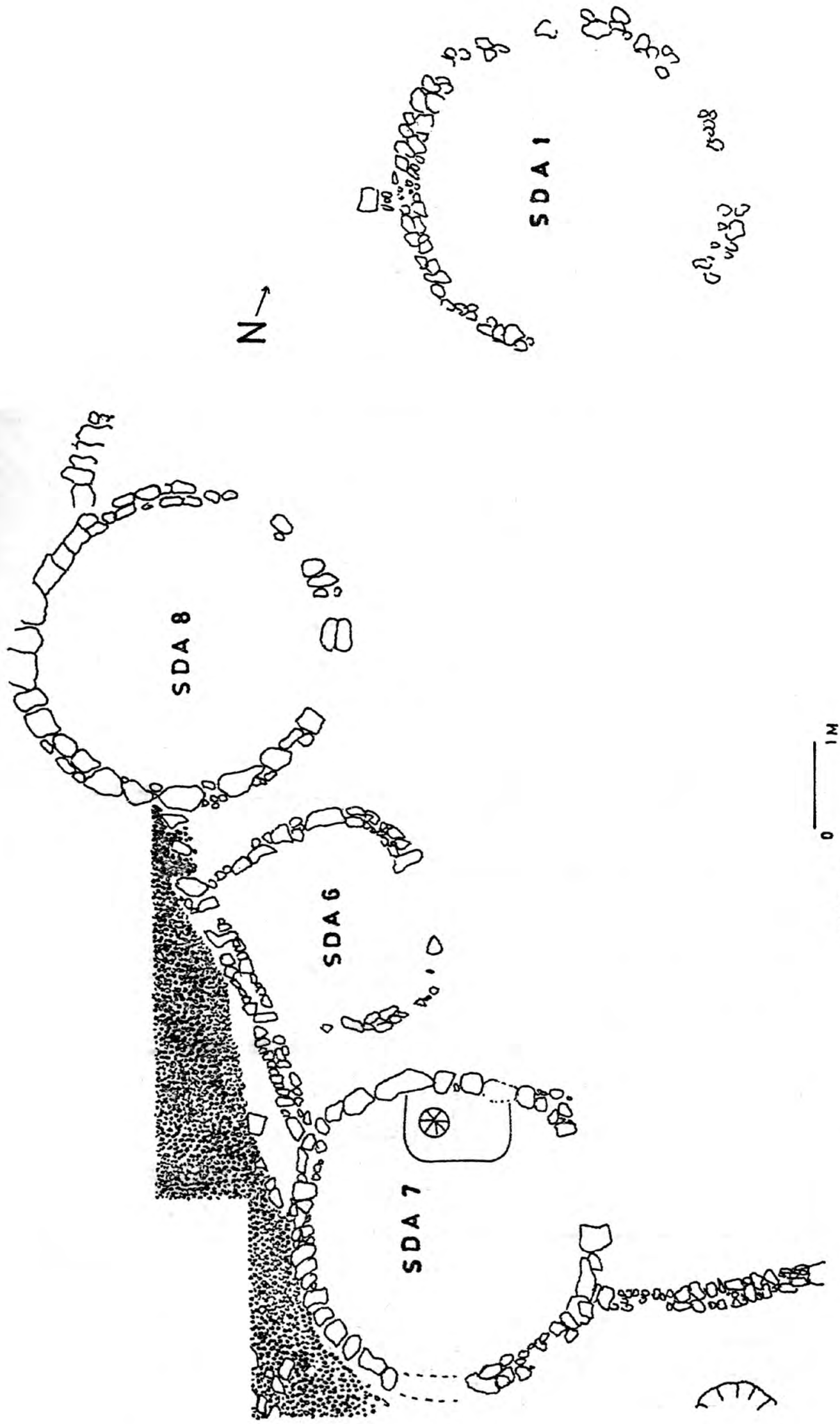


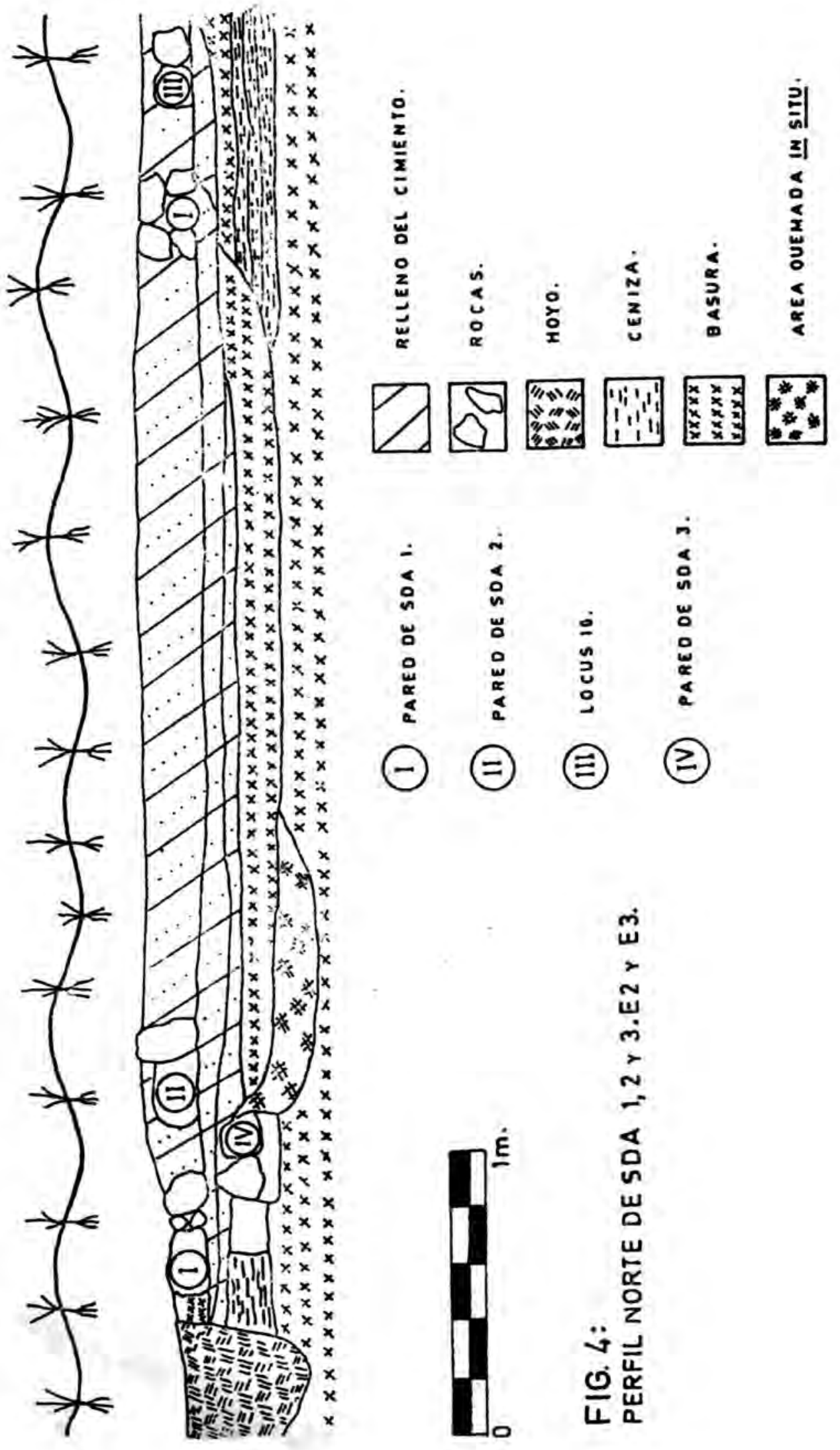



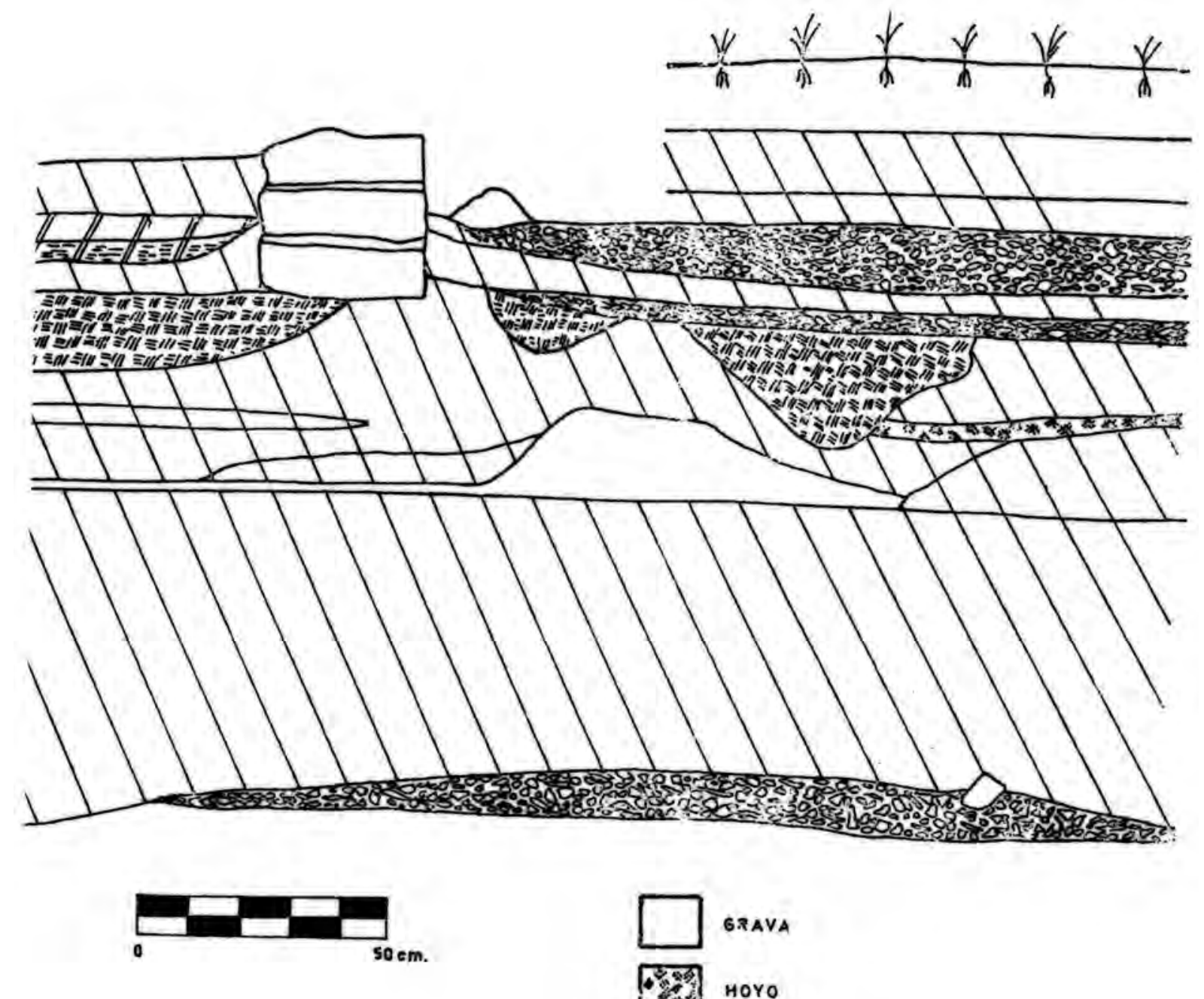

GRAVA

HoYo

FIG. 5: PANCÁN. SDA 7,

$\triangle$ B 4. PERFIL SUR

RELLENO DEL GIMIENTO.

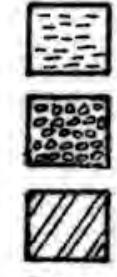

CENIZA.

pieoras.

D SUELO, NATURAL DEPOSITADo POR

ato area quemada in SITU.

S[] rochs. 


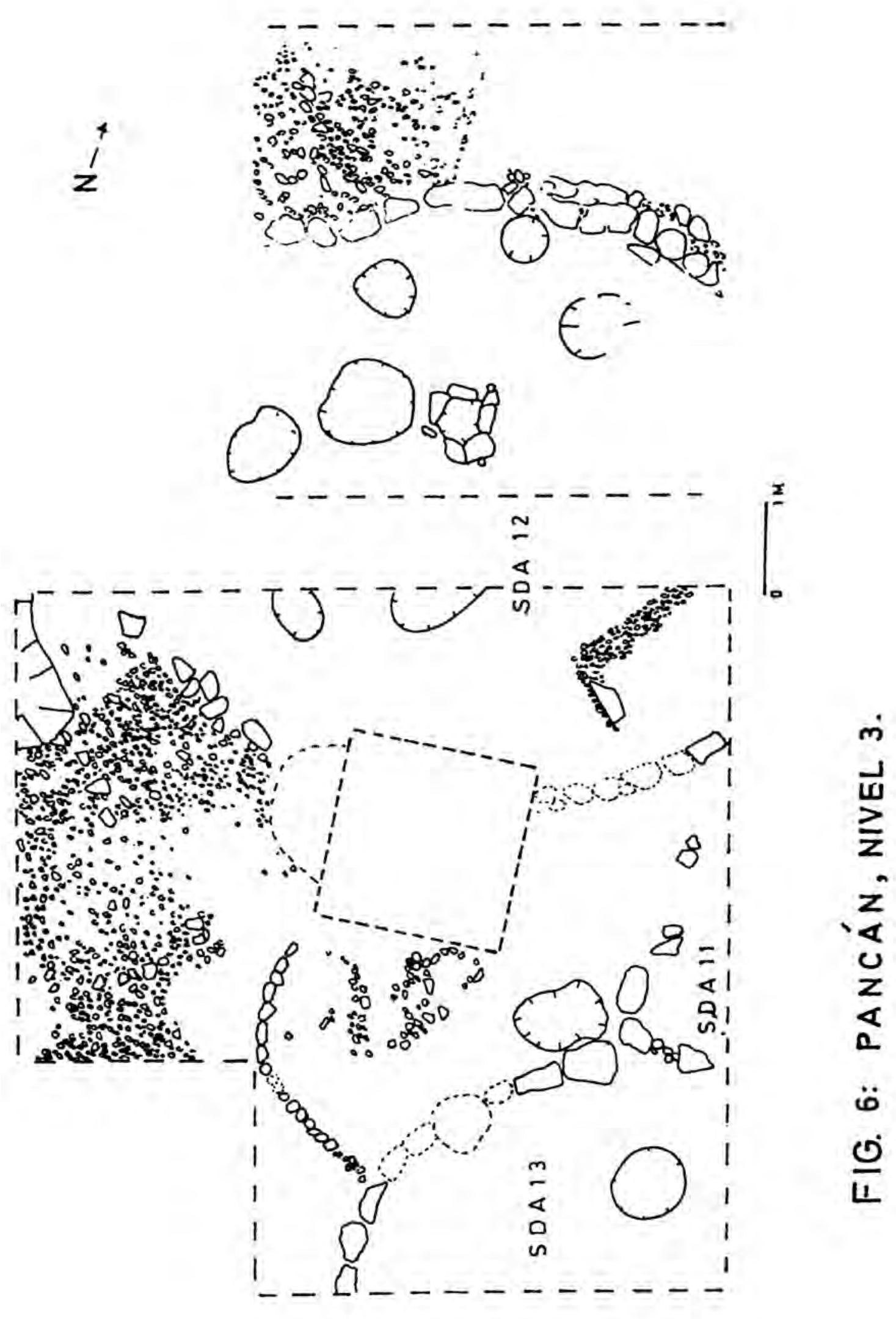




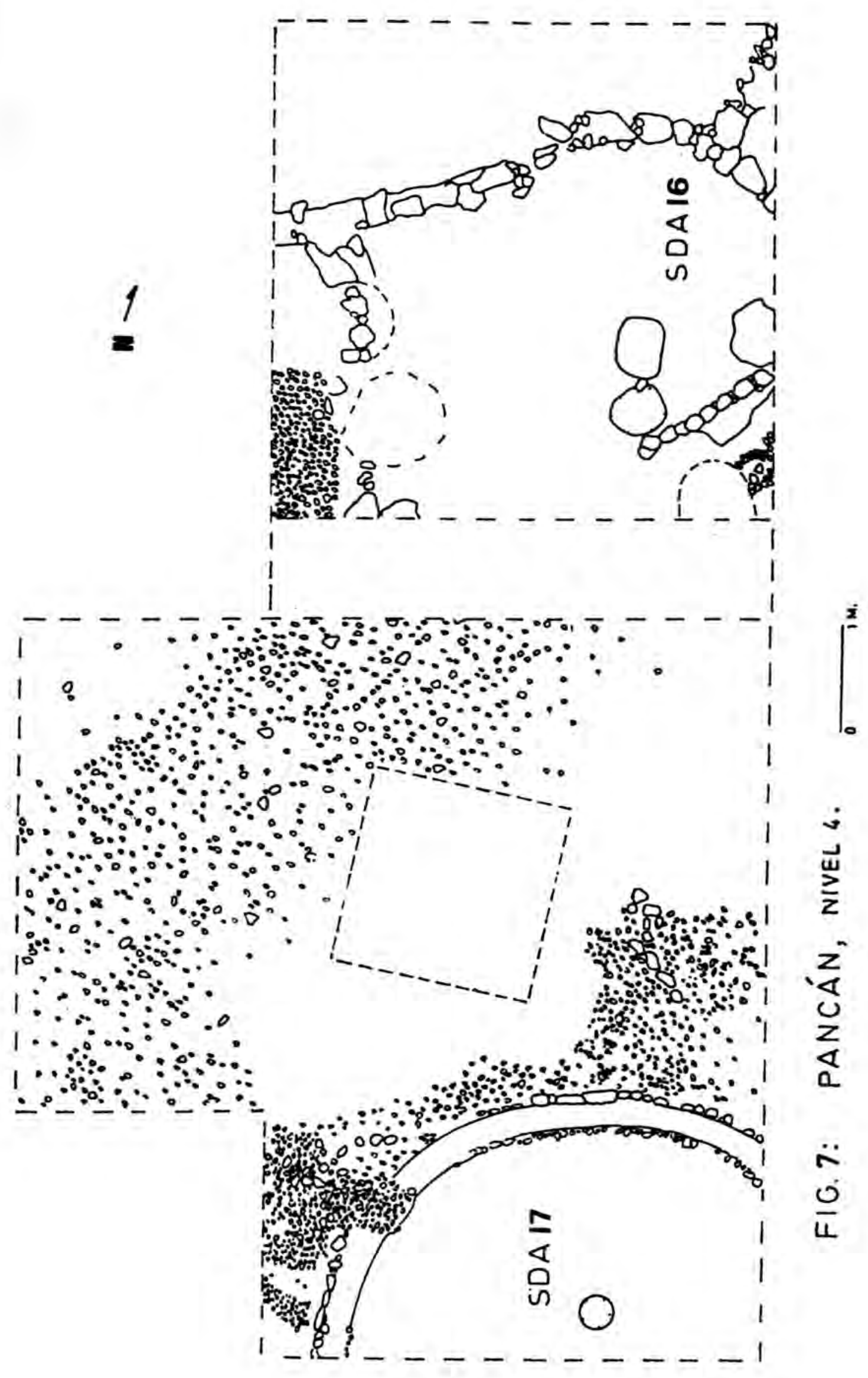


a

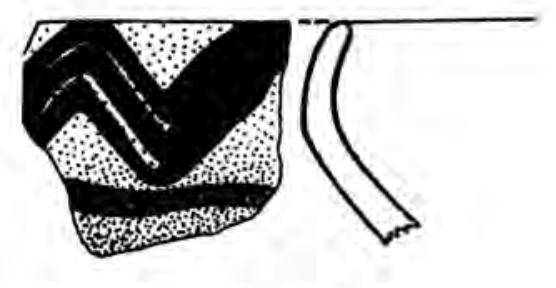

b

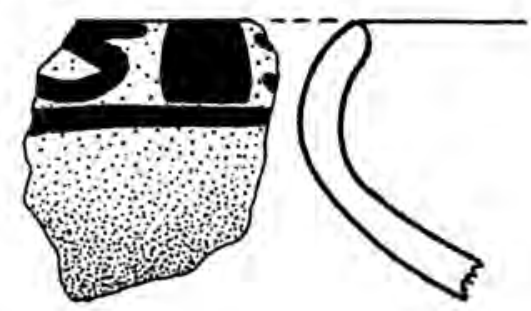

C

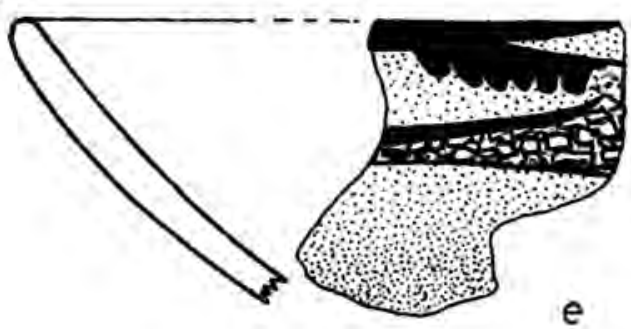

1

e
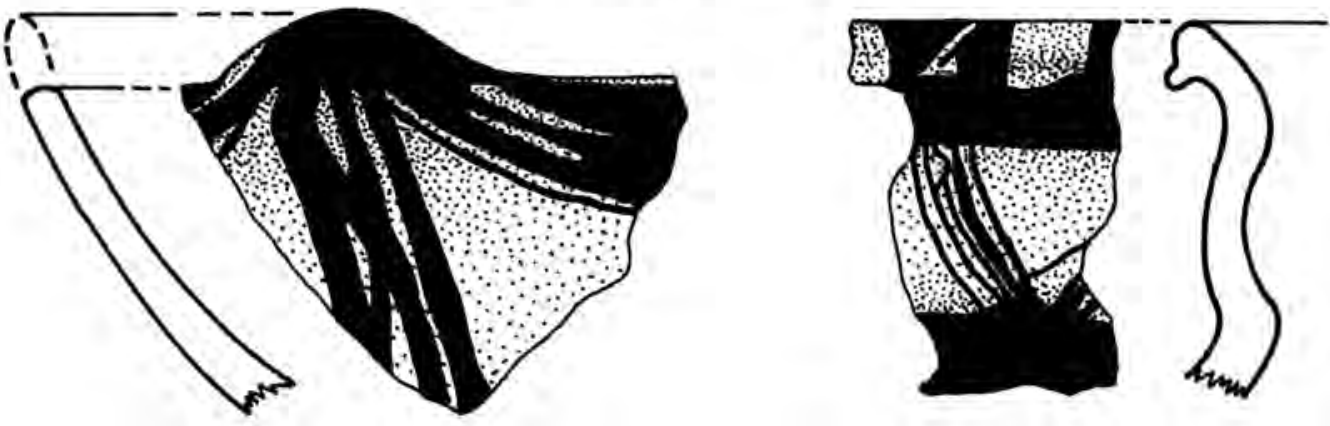

f
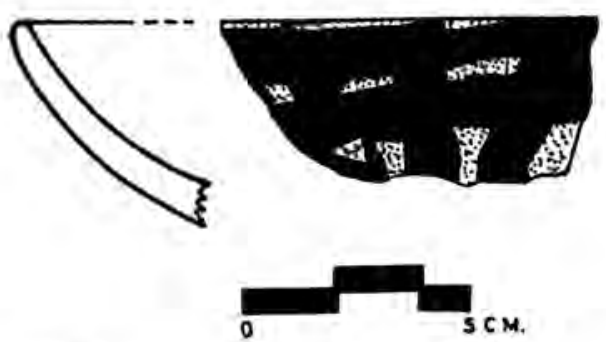

g

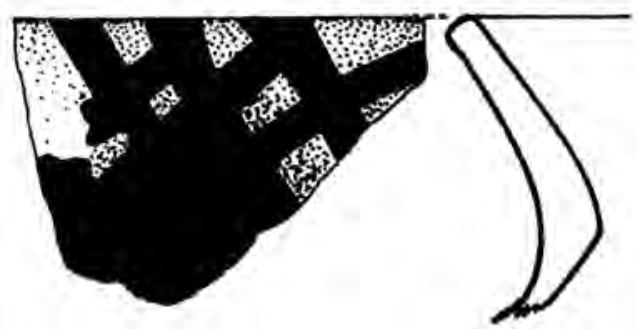

FIG. 8:

a) COCHACHONGOS ROJOINEGRO SOBRE ANTE NATURAL,

b) COCHACHONGOS PÚRPURA SOBRE ANTE.

C) ALFAR ROSAOO, PÚRPURA, SOBRE NATURAL.

d) HUACRAPUKIO PÚRPURA SOBRE NARANJA MATURAL.

c) HUACRAPUKIO PÚRPURA SOBRE ENGOBE NARANSA.

f) WANKA PÚRPURA SOQRE ANIE NATURAL.

D) PÚRPURA ANOESTTA SOSRE ANTE NATURAL.EL COLOR NEGRO OE LOS DIBUJOS REPRESENTA AL PIJRPURA. 


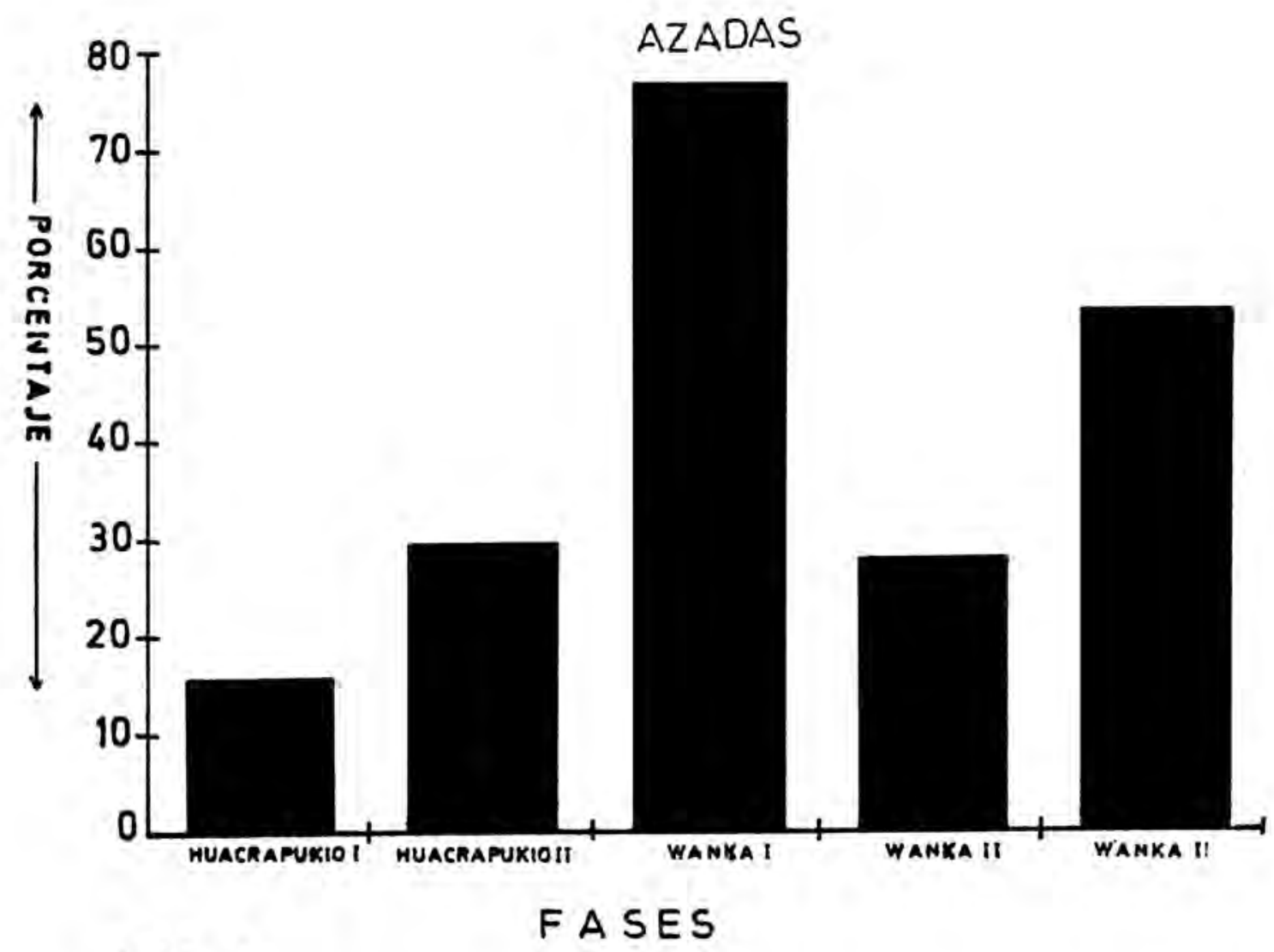

FIG. 9:

PRESENCIA PORCENTUAL DE AZADAS EN LA SECUENCIA; INCLUYE MATERIALES DE SUPERFICIE Y EXCAVACIÓN. 


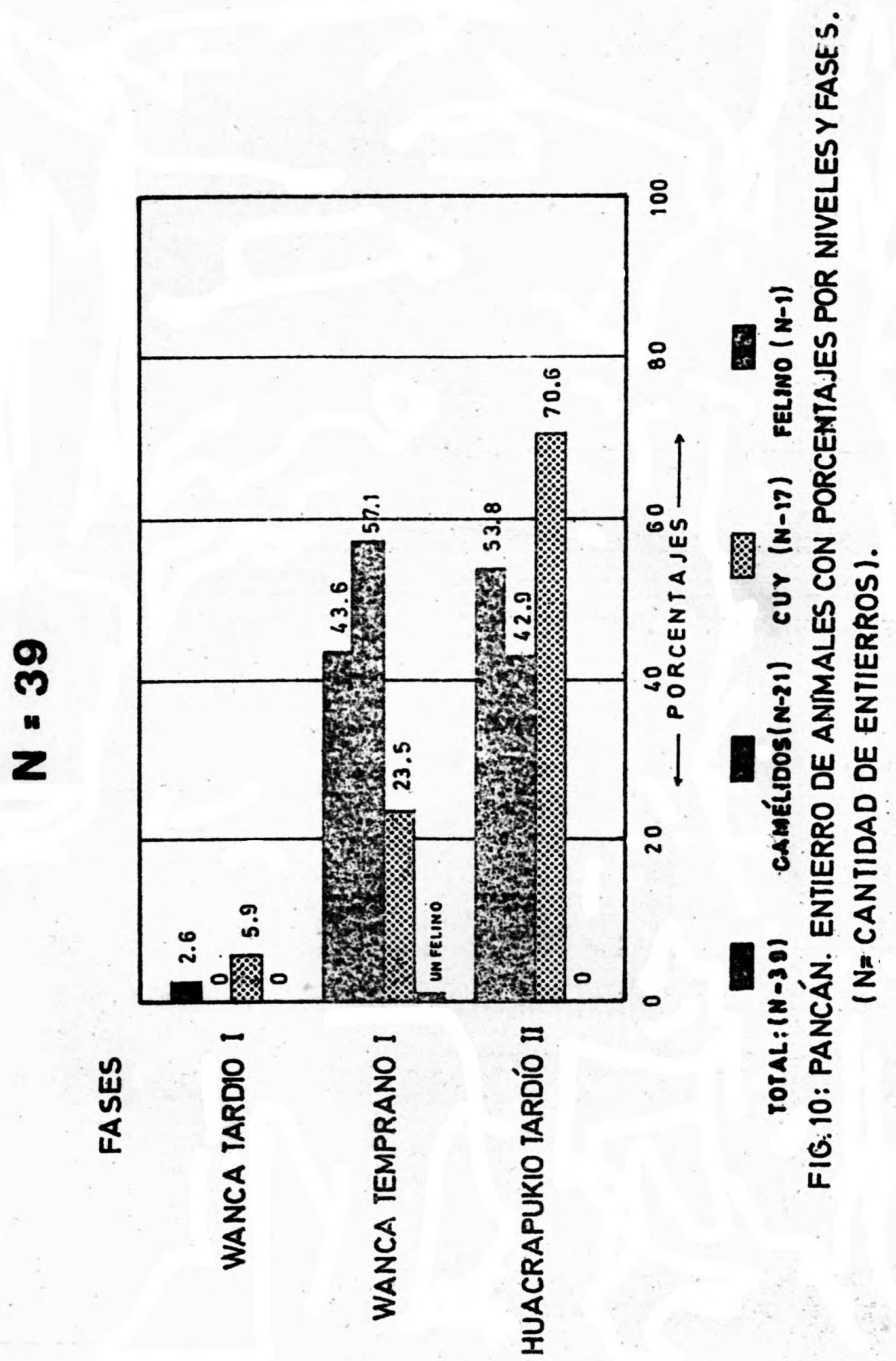

